\title{
Epistemic Tools and Epistemic Agents in Scientonomy
}

\author{
Paul Patton
}

IHPST, University of Toronto paul.patton@mail.utoronto.ca

\section{Keywords}

theoretical scientonomy, epistemic tools, epistemic agents, individual epistemic agents, communal epistemic agents, authority delegation, tool reliance

\section{Abstract}

The only subtype of epistemic agent currently recognized within scientonomy is community. The place of both individuals and epistemic tools in the scientonomic ontology is yet to be clarified. This paper extends the scientonomic ontology to include epistemic agents and epistemic tools as well as their relationship to one another. Epistemic agent is defined as an agent capable of taking epistemic stances towards epistemic elements. These stances must be taken intentionally, that is, based on a semantic understanding of the epistemic element in question and its available alternatives, with reason, and for the purpose of acquiring knowledge. I argue that there can be both communal and individual epistemic agents. Epistemic agents are linked by relationships of authority delegation based on their differing areas of expertise. Having established the role of epistemic agents in the process of scientific change, I then turn to the role of epistemic tools, such as a thermometer, a text, or a particle accelerator in epistemic activities. I argue that epistemic tools play a different role in scientific change than do epistemic agents. This role is specified by an agent's employed method. A physical object or system is an epistemic tool for some epistemic agent if there is a procedure by which the tool can provide an acceptable source of knowledge for answering some question under the employed method of the agent. An agent is said to rely on such a tool. 


\section{Introduction}

Can authority be delegated to tools, like a particle accelerator, a telescope, a text, or a database, just as it is delegated to epistemic communities? The question of authority delegation to artifacts was first raised in a scientonomic context by Nicholas Overgaard and Hakob Barseghyan in the scientonomy seminar in 2016. It prompts an in-depth discussion of a more general question concerning the role of tools and instruments in the process of scientific change. The importance of physical tools and artifacts for observation, measurement, recording, computation, as an aid to reasoning, and as a means of disseminating ideas during theory construction and assessment is clear. Galileo's use of the telescope and Tycho Brahe's careful measurements with quadrants and sextants, the recording of their observations with quill and paper, their calculations with these same implements, and the dissemination of their work as printed text on paper clearly played a part in the acceptance of heliocentric astronomy. Quality nineteenth-century microscopes and skilled anatomical drawings were vital to Theodor Schwann and Matthias Schlieden's theory that all living organisms are composed of cells. A global network of satellites and weather stations, powerful digital computers and computational models, the recording of data in databases stored on hard drives, and the publication of scientific papers accessible via the internet are central to the formulation and assessment of modern theories of global climate change. Even in the formal sciences, physical tools are essential to all but the most rudimentary mathematical and logical computations because of the limitations of human memory and computational ability. These tools include paper and pencil, blackboard and chalk, and digital computers. While the use of tools for cognition, observation, and measurement is the subject of a growing body of literature in the philosophy of cognitive science (Clark, 1998; 2007; 2008; 2010; Giere, 2002; 2004; 2007; Palermos, 2011; Theiner, 2014), an account of such tools in scientonomy has not yet been developed.

Scientonomic discussions concerning entities and relations that take part in the process of scientific change have, so far, focused primarily on epistemic elements, i.e. on theories, questions, and methods (Barseghyan, 2015; Sebastien, 2016; Rawleigh, 2018; Barseghyan, 2018). As for epistemic agents, the only members of that class recognized within scientonomy are communities (Barseghyan, 2015, pp. 43-52). Overgaard (2017) has

Epistemic elements have propositional or interrogative semantic content and are typically expressed sententially by oral or written language (McGrath, 2018), or by means such as visuographic diagrams (Kirsh, 2010; Larkin \& Simon, 1987; Shin, Lemon, \& Mumma, 2018). The epistemic element itself, however, is not to be confused with its physical instantiation. It is, rather, the semantic content that such physical instantiations convey.

defined community as a group that has a collective intentionality, i.e. a shared commitment to a common goal. Overgaard proposed a further distinction, which has not yet been accepted in scientonomy, between epistemic community and non-epistemic community, the former defined as a community that has a collective intentionality to know the world (Overgaard, 2017). Importantly, the place of both individuals and epistemic tools in the scientonomic ontology is yet to be clarified.

This main goal of this paper is to provide a scientonomic account of the respective roles of individuals, communities, and physical tools in the process of scientific change. First, I argue that not only communities but also individuals can be epistemic agents. Second, I show that epistemic tools are not epistemic agents. Instead, I show that epistemic tools play a distinct role prescribed to them by employed methods. I argue that a new relationship, which I will call tool reliance, exists between epistemic agents and epistemic tools. This relationship is not reducible to other relationships currently accepted within theoretical scientonomy, including that of authority delegation.

\section{Epistemic Agents}

The concept of an epistemic agent was made reference to by Barseghyan (Barseghyan, 2018), but it currently lacks a scientonomic definition. Thus, my initial task here is to provide a proper scientonomic definition of epistemic agent. A clear definition of the term is necessary if we are to clarify whether individuals and/or 
epistemic tools can be epistemic agents. But in order to have a viable definition of epistemic agent, we should first consider the more general concept of agent.

The term agent is standardly defined as an entity capable of intentional action (Schlosser, 2015). Intentionality is the property possessed by representational states or states with content or meaning. These states are about something. Mental states, like perceptual states or belief states, are examples of states that possess intentionality (Jacquette, 2006; Neander, 2018; Dretske, 1981, pp. 63-82; Dennett, 1971; Millikan, 1984, pp. 85-94; Overgaard, 2019, pp. 65-70). They are no longer regarded as the only such states. Many philosophers also regard external symbols with semantic content, such as written text on paper, instrument readings, and computer displays as exhibiting a kind of intentionality (Dretske, 1981; Jacob, 2019). In addition to internal and external states related to cognition, other biological states, such as the arrangement of nucleotide base pairs in the genome of an organism, are also said to possess intentionality (Fitch, 2008; Godfrey-Smith \& Sterelny, 2016). Such states may perform the function of containing semantic information for the system of which they are a part (Dretske, 1981),

The term information has been used in a variety of ways. Claude Shannon's information theory, intended for use by communications engineers, carries no connotations of semantic content. The relationship between information and intentional semantic content, useful for philosophical, cognitive science, and biological applications, has been explored by Dretske (Dretske, 1981; 1983). His conception is the one I generally have in mind here. and perform biological or other functions for that system (Godfrey-Smith, 2006; Godfrey-Smith \& Sterelny, 2016; Millikan, 1984).

When we say that an agent's actions are intentional, what we mean is that they are purposeful, directed towards a goal, or performed for a reason. This may be because they are caused by the agent's mental states (Schlosser, 2015), or because they simply exhibit the right sort of organization (Dennett, 1971; 1987). Some have argued that agency is a universal feature of living systems, evident even in the flexible goal-directed behavior of cells and bacteria (Walsh, 2015, pp. 208-229; Fitch, 2008; Fulda, 2016; 2017; Walsh, 2018), and that a derived form of agency is present even in some goal-seeking engineered systems such as thermostats (Dennett, 1987, pp. 37-42). The concept of agency has traditionally been problematic for naturalists, since it seems to involve dualistic notions of irreducible mental causation (Jacquette, 2006; Schlosser, 2015), or a particular folk psychological conception of beliefs and desires (Churchland, 1981). However, a number of authors have proposed naturalistic understandings of agency, in which intentional states supervene on appropriate physical states, or are simply a way of interpreting those physical states, and mental or intentional causation is simply a species of physical causation. Such causation is by the dynamical state of an appropriately organized physical system, such as an organism and its brain in interaction with the world (Dennett, 1984; 1987; 1991; 2003; Fulda, 2016; Giere, 2004; Schlosser, 2019; Walsh, 2012; 2018; Walter, 2009). These accounts render the concept of agency more comprehensible and hence more attractive for scientonomic use.

Here, following standard practice, I define agent as an entity capable of intentional action (Schlosser, 2019). What this means is that, given the naturalistic concept of intentionality referenced above, an agent perceives their environment and acts within it with a motive or in pursuit of a goal, choosing among multiple courses of action so as to best fulfill their goal. Human beings, and many other living things, would clearly qualify as agents under such a definition of agency (Dennett, 1983; Fitch, 2008; Fulda, 2017; Walsh, 2018).

We can usefully draw on this general definition of agent in formulating a definition of epistemic agent. Rather than acting in relation to an environment in general, an epistemic agent acts in relation to epistemic elements such as theories, questions, and methods. The actions of an epistemic agent amount to taking epistemic stances towards these elements, such as accepting or pursuing a theory, employing a method, etc.

\begin{tabular}{|c|c|}
\hline Agent $\equiv$ & \multicolumn{1}{c|}{ Epistemic Agent $\equiv$} \\
\hline $\begin{array}{c}\text { An entity capable of } \\
\text { intentional action. }\end{array}$ & $\begin{array}{c}\text { An agent capable of taking epistemic } \\
\text { stances towards epistemic elements. }\end{array}$ \\
\hline
\end{tabular}


Now, to qualify as an epistemic agent, the taking of an epistemic stance must be intentional. Thus, the following two conditions must be met:

1. the agent must have a semantic understanding of the propositions that constitute the epistemic element in question and of its available alternatives;

2. the agent must be able to choose from among the available alternatives with reason, and for the motive of acquiring knowledge.

Goldberg (2016) notes that epistemic agency involves epistemic norms. In scientonomic terms, the normative epistemic strategy which the agent deploys in such an assessment is its method (Barseghyan, 2018).

It should be clear that, under this definition of epistemic agent, most individual human beings can qualify as epistemic agents whenever they engage in the pursuit of knowledge. First, it is evident that a typical individual, given appropriate education and training, can semantically understand the propositions which constitute the epistemic element in question, and its alternatives. In addition, a typical individual can choose among alternatives with reason. Finally, a typical individual can pursue the goal of acquiring knowledge. Therefore, it is safe to say that individuals can typically function as epistemic agents. The argument may be summarized as follows:

To qualify as an epistemic agent, an agent must have a semantic understanding of the propositions which constitute the epistemic element in question, and of its alternatives, and must be able to choose among them with reason, with the goal of acquiring knowledge.

A typical individual human, given appropriate education and training, can semantically understand the propositions which constitute the epistemic element in question, and its alternatives.

Individual humans can be epistemic agents.

A typical individual human can choose among alternatives with reason.

A typical individual human can pursue the goal of acquiring knowledge.

If we take propositions to be sentential and linguistic, then the definition excludes most or all non-human animals. The only human individuals excluded, in the absolute sense, from the definition of epistemic agent are those who are wholly incapable of semantically understanding propositions, such as pre-linguistic infants and persons with severe cognitive deficiencies due to neurological conditions.

In scientonomy, communities have been taken as the primary focus of interest for understanding the process of scientific change (Barseghyan, 2015, pp. 43-52); it is currently accepted that communities can be epistemic

The applicability of the definition may also vary as a matter of degree, since individuals may differ one from another in the depth of their semantic understanding of the epistemic element in question, and of other contextually relevant epistemic elements. Such differences might be produced, for example, by scientific or professional training. An individual's merits as an epistemic agent will be assessed by others based on whether their claims can satisfy the requirements of the method employed by those others. The issues raised by norms of merit are best understood in terms of the concept of authority delegation to be discussed further below. agents. At this stage, we need to ensure that communities can still qualify as epistemic agents under the new definition of epistemic agent. According to the current definition of community, communities are characterized by a certain collective intentionality (Overgaard, 2017). Thus, to determine whether communities can be epistemic agents, we have to analyze the notion of intentionality. In the scientonomic context, the notion of intentionality has been previously explored by Overgaard $(2017 ; 2019)$. 
In my discussion, I will draw upon Overgaard's analysis as well as the ideas proposed by Wimsatt $(2006,2007)$ and Theiner and O'Connor (2010).

As shown by Overgaard (2019, pp. 1-64), some commentators maintain that the social agents of science should be understood as networks of individual practitioners exchanging and transforming scientific knowledge, practices, and materials, rather than as communities (Barnes, 2013; Latour, 1987; 2005; Latour \& Woolgar, 2013). Others, however, stress the existence of communities united by a shared conceptual framework of qualities, like common beliefs and values, and a shared institutional structure (Galison, 1987; 1995; 1997). The idea of communities as ontological elements and as agents has been developed in depth by social ontologists (Lawson, 2014; Searle, 1995; 2006; Tollefsen, 2014; Tuomela, 2002). These ideas have been applied to epistemic communities by a number of authors (Overgaard, 2017; 2019; Palermos \& Pritchard, 2016; Palermos, 2016; Theiner \& O'Connor, 2010; Tollefsen, 2004, 2006).

As social ontologists have defined it, a community is a group of agents who possess a collective intentionality, that is, they pursue a shared common goal or goals (Overgaard, 2017; 2019). An epistemic community, as Overgaard (2017) defined it, is one with a collective intentionality to know the world. The building blocks of such

Overgaard did not provide a definition of scientific community, since this would require demarcation criteria by which one might distinguish science from non-science (Overgaard, 2017). Such demarcation criteria have varied over history and across communities. Thus, distinguishing a scientific community from a non-scientific one may not be appropriate for scientonomic purposes.

a community are individuals that themselves have an intentionality to know the world. But collective intentionality is not simply shared intentionality or the sum of separate individual intentions. For the intention to be collective, individuals must work together through their coordinated actions to achieve shared goals. For example, a research team might coordinate their actions to perform a single experiment, each making their own distinctive contribution towards its success. The outcome might be a single co-authored published paper containing theories accepted by the entire team.

For an epistemic community to qualify as an epistemic agent, it must be capable of taking stances towards an epistemic element and these stances must be the result of semantic understanding of the epistemic element and its available alternatives. There are good reasons to suppose that this capacity is typical of epistemic communities. Systems of multiple interacting parts, if those parts are appropriately organized in relation to one another, often exhibit emergent properties that are not those of their constituent parts (Bedau, 2002; Kim, 1999; O'Connor, 2015; Wimsatt 2006; 2007, pp. 274-312). A number of authors have argued that epistemic communities appear to be systems of the requisite sort needed to possess emergent properties (List \& Pettit, 2006; 2011; Palermos \& Pritchard, 2016; Palermos, 2016; Theiner, 2015; Theiner, Allen, \& Goldstone, 2010; Theiner \& O’Connor, 2010).

Following Theiner and O'Connor (2010), we can justify the notion that an epistemic community's capacity of taking epistemic stances is an emergent property by considering the work of Wimsatt (2006; 2007). He defined the emergent properties of a system as those that depend on the way its parts are organized. When concerned with emergence as Wimsatt understands it, we are therefore concerned with the relationship between the properties of a whole system, and the properties of its constituent parts. Aggregate systems are those in which parts do not bear an organized relationship to one another. The parts all play similar causal roles and can be interchanged or rearranged without consequence. The behavior of the whole is an additive, statistical consequence of the behavior of its parts and no emergent properties are present. A jumbled pile of electronic parts is an example of an aggregate system. Its properties, such as its mass or its volume, are simply the sum of the masses or the volumes of all the parts. A composed system possesses new emergent properties due to the way in which its parts are organized in relation to one another. A radio assembled by arranging the electronic parts in the proper relationship to one another is an example of a composed system. The ability to be a radio is an emergent property, because none of the radio's parts exhibit it by itself. The parts are organized so that each one comes to play its own distinctive, specialized role in the production of the emergent property.

There are good reasons to regard the decision-making processes of epistemic communities as those of a composed system. A communal epistemic agent is an organized system of individual epistemic agents, each of which makes their own distinctive contribution to the epistemic stances taken by the communal agent as a whole. 
These roles are determined by institutional and other forms of organization of the communal agent, and typically involve varied and complementary areas of specialized knowledge. Collective decision-making processes and institutional frameworks interact with and influence the views of individual community members. These allow a community to take epistemic stances towards epistemic elements that are distinct from those that its individual members might take if left to their own devices. These stances are thus not a simple aggregate of individual views.

In an analysis of legal decision-making processes, Tollefsen (2004) has shown that there are a variety of circumstances under which a community's epistemic stances are not the simple aggregate of its individual member's stances. Longino $(1990 ; 2019 ; 1996)$ maintains that, when communities have normatively appropriate structures, critical interactions among community members holding different points of view mitigate the influence of individual subjective preferences and allow communities to achieve a level of objectivity in their taking of epistemic stances that is not generally possible for individual agents. Barseghyan (2015, pp. 43-52) has argued that the methods used by individual prominent scientists often, in fact, do not coincide with those of their community, and that a community's acceptance of a theory is a function of the methods employed by that community rather than of individual idiosyncrasies. Thus, as required by the definition, it appears that most epistemic communities are communal epistemic agents that can take epistemic stances. This is due to a community's collective intentionality to know the world, and a composed organization which give its members distinctive roles in the formation of collective epistemic stances. These arguments for the existence of communal epistemic agency can be summarized as follows:

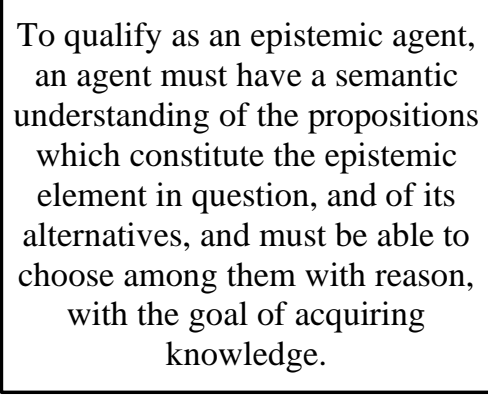

An epistemic community includes individual epistemic agents who can, by definition, semantically understand the epistemic element in question, and its alternatives. arise due to the way in which its constituent parts are organized.

They are properties of the system as a whole.

An epistemic community
typically has its own
institutional framework, division
of epistemic labour, and
collective decision-making
processes. This organization
makes the community a
composed system.

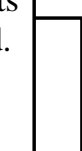

\footnotetext{
$\square$
}$$
\rightarrow
$$

An epistemic community can make reasoned epistemic choices that belong to the community as a whole rather than to its constituent agents.

Epistemic communities, by definition, have a collective intentionality to know the world.

Therefore, they can be said to possess the goal of acquiring knowledge.
Epistemic communities can be epistemic agents.

Now, if one takes a naturalistic view of epistemic agency, then both communal and individual epistemic agents can be seen as composed systems whose capacity to take epistemic stances is an emergent property. The epistemic 
stances of a communal epistemic agent arise from the organized interactions of its parts, at least some of which are themselves epistemic agents. The epistemic stances of an individual epistemic agent are also an emergent property of a composed system arising through organized interactions between its parts, which are in this case living cells. But while the two levels of organization resemble each other in that they are both composed systems, it is also important to take note of the ways in which they are profoundly different. First, it has been plausibly argued that the living cells that make up an individual epistemic agent possess a rudimentary form of both intentionality and agency, since they can rearrange their own structure in response to damage, nutrient distribution, or other environmental features (Fitch, 2008; Fulda, 2017). Nevertheless, unlike the constituent parts of a communal epistemic agent, they are clearly not themselves epistemic agents. Secondly, the number of constituent living cells that make up an individual epistemic agent is vastly larger than the number of individual epistemic agents that could make up any known communal epistemic agent. The most relevant such living cells are the 86 billion neurons that constitute the human brain (Bechtel, 2008; Clark, 1998; Deacon, 2012; HerculanoHouzel, 2009; Thompson, 2007; Walter, 2009).

The nature of the relationship between individual epistemic agents and their constituent brain cells is a matter primarily of interest to cognitive neuroscientists. The example, however, calls attention to another relationship that is of more direct scientonomic concern, and this is the relationship between individual epistemic agents and communal epistemic agents. The example illustrates that entities at different levels of organization in a composed system can have very different properties. I have argued that both individual and communal epistemic agents possess the defining qualities of epistemic agency, but beyond that we should not necessarily expect them to have all of the same properties. Scientonomy, in its current form, asserts that the taking of epistemic stances by epistemic communities is a lawful process governed by laws of scientific change (Barseghyan, 2015, pp. 43-52, 123-164). It is not yet at all clear whether the taking of epistemic stances by individuals acting independently is likewise constrained by the same laws or is instead highly idiosyncratic. Both Longino (1990, pp. 62-82) and Barseghyan (2015, pp. 43-52), for example, have stressed the social nature of theory assessment in accordance with a normative method. The question of whether or not the laws of scientific change (Barseghyan, 2015, pp. 123-164; Sebastien, 2016; Patton, Overgaard, \& Barseghyan, 2017) apply to the taking of epistemic stances by individuals is an important and as yet unanswered scientonomic question. What's important for the present discussion is that both individuals and epistemic communities can be epistemic agents.

Now, if we accept that epistemic agents can be not only communal but also individual, we have to redefine the concept of authority delegation as well as all the derived concepts. The current scientonomic definition of authority delegation, formulated by Overgaard and Loiselle (2016), characterizes it as a relationship between communities. Yet, interestingly, using examples from the community of art experts, Loiselle (2017) has previously showed that an individual can be the subject of authority delegation. Especially within the research groups of individual scientific labs, authority delegation to individuals is likely to be ubiquitous. The substance of the Overgaard and Loiselle (2016) definition requires no alteration, but I propose that epistemic agents should be substituted for communities in the definition to allow that delegation of authority can be to either individual or communal epistemic agents, thereby ensuring its comprehensive usefulness:

\begin{tabular}{|c|}
\hline Authority Delegation $\equiv$ \\
\hline Epistemic agent A is said to be delegating authority over \\
question $x$ to epistemic agent B iff (1) agent A accepts that \\
agent B is an expert on question $x$ and (2) agent A will \\
accept a theory answering question $x$ if agent B says so. \\
\hline
\end{tabular}

Note that the new definition also substitutes question for topic. While question is currently defined as "a topic of inquiry" (Rawleigh, 2018, p. 2), question is the proper scientonomic category here, so it is the one that should be used in the definition. Similar substitutions are necessary in the definitions of all subtypes of authority delegation,

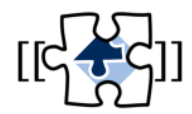
including mutual authority delegation, one-sided authority delegation, singular authority delegation, multiple 
authority delegation, hierarchical authority delegation, and non-hierarchical authority delegation. Since these substitutions are rather trivial, I won't present the new definitions here, but will only include them in the respective suggested modification.

Note that the concept of authority delegation is reducible to theories and methods. This is illustrated with a familiar example taken from Loiselle (2017). The art market community - the community responsible for buying and selling works of art - accepts the theory that the Wildenstein Institute is an expert on determining the authenticity of Monet paintings. Its employed method is therefore to accept the authenticity of a Monet painting if the institute says it is authentic. The Wildenstein Institute, in turn, has its own method of authentication. Its authority rests on the ability to justify this method, and its application to any individual case, in terms of the theories from which it was deduced.

\section{Epistemic Tools}

Having defined the concept of epistemic agent and clarified the concept of authority delegation, we can now turn to our primary interest - the role of physical tools and artifacts in the process of scientific change. Before considering the role of epistemic tools in scientonomic theory, we need to clearly identify this class of entities by considering some examples.

Primatologist Jane van Lawick-Goodall (Bentley-Condit \& Smith, 2010; van Lawick-Goodall, 1970) defined tool use as: "use of an external object as a functional extension of mouth or beak, hand or claw, in the attainment of an immediate goal". Tool use, as so defined, has been noted in a variety of animal species (Bentley-Condit \& Smith, 2010). In the case we are considering, the "immediate goal" is the acquisition, dissemination, or preservation of knowledge, and therefore the sort of tool we have in mind will be referred to as an epistemic tool. Such epistemic tools are extremely varied.

To understand the basic concept, we will start with the simple example of a found object used as an epistemic tool. Consider a pit, the bottom of which is hidden in darkness. The depth of such a pit can be roughly estimated by dropping a stone down the pit and noting how much time passes before one hears the stone hit the bottom of the pit. In scientonomic terms, this amounts to

In scientonomy, knowledge is taken to be propositional, and perhaps, sentential and linguistic. When knowledge is understood in this way, language-capable human beings are likely to be the only animals capable of making epistemic tools. However, if a broader understanding of knowledge is adopted, then the possibility that some non-human animals make epistemic tools may warrant consideration. For example, gorillas have been reported to use a stick to learn the depth of water, for the sake of safely crossing streams rather than formulating propositions (Breuer, NdoundouHockemba, \& Fishlock, 2005). Such examples warrant further investigation, as they may provide clues to the evolutionary roots of the foundational human capability of making epistemic tools. employing a method that says "A rough estimate of a pit's depth is acceptable if it was measured by dropping a stone down the pit and noting how much time passes before one hears the stone hit the bottom of the pit". Now, by the law of method employment (Sebastien, 2016), this method is a deductive consequence of a number of theories, such as "when a stone is dropped down a pit, it will take longer to reach the bottom if it is deep than if it is shallow" and "a stone typically makes a sound when it hits the bottom of a pit":

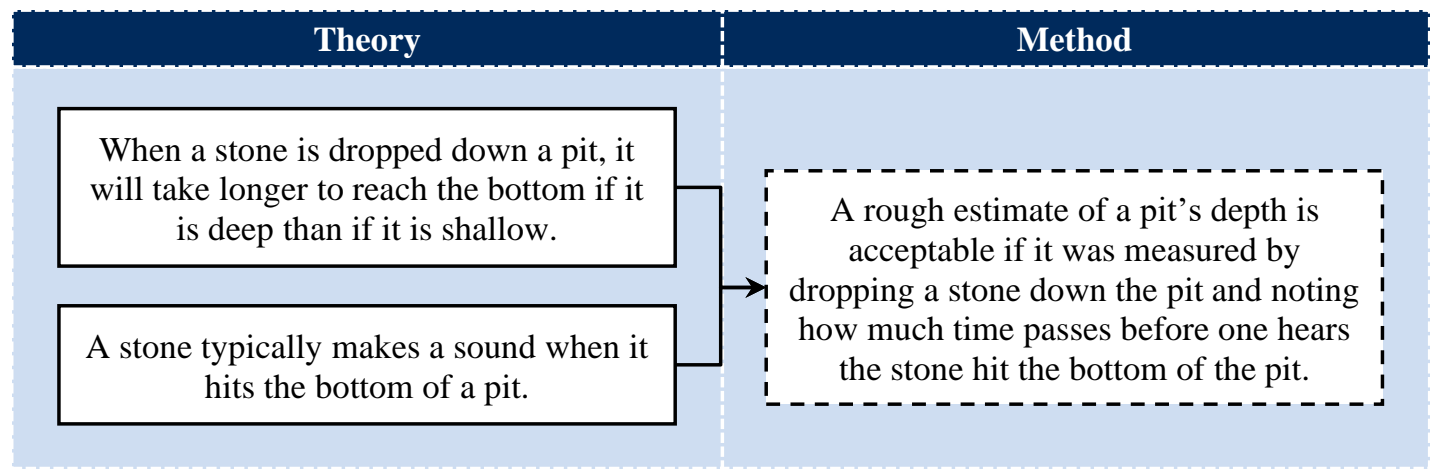


The idea that natural environments contain semantically meaningful information accessible to perception was originally advocated by the psychologist James. J. Gibson (Gibson, 1967; 1979; 2002), and later advocated in another form by Dretske (Dretske, 1981; 1983). In Gibson's version, it was the ecological needs of an animal perceiver that conferred semantic meaning on the features of the environment, rather than an explicit theory as posited here, or the worldly regularities posited by Dretske.
Importantly, in this example, the stone plays the role of an epistemic tool in proper accordance with the normative procedure expected under the employed method. More generally, the procedure follows from accepted theories concerning the epistemic tool. An employed method derived from these accepted theories stipulates that the procedure ought to be regarded as an acceptable source of

knowledge. Note that the theories and their associated method renders the relevant behavior or properties of an epistemic tool semantically meaningful to an epistemic agent, who employs the requisite method, as providing knowledge. That is, it endows the relevant behavior or properties of the tool with intentional content, as intentional content is understood under the theories of Dretske $(1981 ; 1983)$.

I can now offer a definition of epistemic tool. A physical object or system is an epistemic tool for an epistemic agent if and only if there is a procedure by which it can provide an acceptable source of knowledge for answering some question under the employed method of that agent:

\begin{tabular}{|c|}
\hline Epistemic Tool $\equiv$ \\
\hline A physical object or system is an epistemic tool \\
for an epistemic agent iff there is a procedure by \\
which the tool can provide an acceptable source \\
of knowledge for answering some question under \\
the employed method of that agent. \\
\hline
\end{tabular}

By a physical system, I simply mean that an epistemic tool can consist of multiple interacting parts. To indicate epistemic tools on scientonomic diagrams, I suggest using the following symbol:

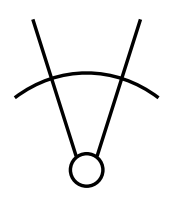

Epistemic tools are a very broad class of tools. While a found object, such as the stone in the example above, may function as an epistemic tool, epistemic tools are often manufactured artifacts made or modified through the workmanship of an agent to perform an epistemic function. They may be carefully designed physical systems with many interacting parts. Some epistemic artifacts simply extend our perceptual capabilities. A stethoscope, for example, augments the capabilities of the human ear, allowing the user to hear faint sounds within the human body. Such faint sounds, according to accepted medical theories, can provide knowledge about bodily health and allow the recognition of indications of a variety of disorders to an appropriately trained user. Other tools which function primarily to extend perception include windows, mirrors, microscopes, telescopes, or a blind person's cane.

Some epistemic tools, like an alchemist's furnace, or the Large Hadron Collider, create special conditions deemed useful to scientific inquiry. The Large Hadron Collider, for example, is designed to accelerate beams of subatomic particles to speeds close to that of light and collide the particles with one another. According to accepted theories, observations of such collisions are meaningful for testing the predictions of physical theories, such as the standard model of particle physics (Mann, 2019).

The words of spoken language are ephemeral and were once the sole means by which propositions could be formulated and communicated. Frail human memory was also, at a time, the only means by which propositions could be preserved. An important group of epistemic tools depend on the ability to represent propositions symbolically in a stable external physical medium, thus endowing that medium with intentional semantic content for an epistemic agent with knowledge of the meaning of the symbols (Jacob, 2019; Nanay, 2006). Such tools 
enable numerous means of individual and communal cognitive enhancement (Donald, 1991, pp. 269-360). Among the propositions that can be represented symbolically are those pertaining to language, mathematics, and logic. Clay tablets, written text on parchment, paper, hard drives, memory sticks, and various other storage and data transmission technologies allow the creation, preservation, and spread of symbols encoding the propositional knowledge of their authors. Such epistemic tools greatly augment the ability to remember and to teach. The texts attributed to the Greek physician Galen of Pergamum are one example of such a tool. For over a thousand years after the author's death, Galen's medical texts were considered authoritative resources on medicine by the medical community of Europe and the Arab-Islamic world. They were used in the instruction of medical students at universities, and practicing physicians referred them in their work of treating patients (Nutton, 2008; Siraisi, 2009; Temkin, 1973).

An important class of symbolic epistemic tools, such as scales, thermometers, and voltmeters, are designed to produce mathematical symbols representing quantities as their output, thereby permitting quantitative measurement. A thermometer's output, for example, may be read as the proposition "The temperature is currently $35^{\circ}$ Celsius". The ability to represent propositions as external symbols also makes it possible for a pencil and paper, an abacus, a slide rule, or a digital computer to enable performing complex multistep mathematical or logical operations that would be impossible using only our unaided memory (Giere \& Moffatt, 2003; Rumelhart \& McClelland, 1986, pp. 44-48). The digital computer also allows vast numbers of such computations to be completed in a short time. In many modern epistemic tools, quantitative measurement, digital computation, and a semantically interpretable output are combined. A DNA sequencer is an example of such an epistemic tool that is widely used nowadays by geneticists to automate the process of determining the sequence of nucleotide base pairs in a gene. The accepted questions about this sequence presuppose theories in genetics and molecular biology. When a prepared sample of DNA is inserted into such a machine, the machine determines the order of the four nitrogenous base pairs in the sample. The design and use of such a device draw on accepted theories in a wide variety of fields, from solid state physics to molecular biology. It reports the base pair sequence as a text string on a computer screen. Such text strings are full of intentional content for a knowledgeable molecular biologist (Heather \& Chain, 2016; Hutchinson, 2007).

In addition to linguistic, logical, and mathematical symbols, diagrams are another important type of external symbolic representation. A diagram is a graphic that represents the arrangement and relations of the parts of some system as the spatial and geometrical relationships of the elements of the diagram. Diagrams appear to long predate the use of linguistic symbols by humans. The ability to create diagrams on rock faces, pieces of ivory, paper, or electronic screens makes it possible to enlist the powerful pattern recognizing abilities of the human visual system for cognitive purposes (Donald, 1991, pp. 269-360; Kirsh, 2010; Tversky, 2014). Some epistemic tools, such as the ancient Greek antikythera mechanism (Seiradakis \& Edmunds, 2018), the clocks and orreries that became popular during the early modern period, or a modern digital computer are designed to produce diagrammatic output automatically.

The highly automated observational techniques used in modern astronomy for ground-based and spacecraft observations provide a particularly sophisticated example of epistemic tools that automatically produce symbols, sentences, and visuographic representations as output. Such techniques generate large databases of observational data with little direct human involvement. A robotic telescope is one whose low-level behavior is automatic and computer-controlled. Such telescopes are used to automatically detect and gather data on a variety of astronomical phenomena. This includes asteroids, comets, other solar system objects, supernovae, stars that vary in brightness, and exoplanets. Given a pool of submitted targets and tasks, such telescopes typically schedule their own observations, based on the Earth's rotation as well as weather and illumination conditions. They are considered especially valuable for detecting and characterizing transient astronomical phenomena (Bakos et al., 2002; Denneau et al., 2013; Drake et al., 2011; Gillon et al., 2011; Granzer, 2004; Las Cumbres Observatory, 2019; Stone et al., 2003).

In addition to possessing a kind of intentionality, many tools, including many epistemic tools, possess a kind of agency under the broad definition of agency given above (I will argue below that historical or current epistemic 
Strictly speaking, a thermostat is not, by itself, an epistemic tool. It is mentioned here because it is a commonly invoked example of an engineered device exhibiting a crude form of agency. While the thermostat does not, by itself, serve an epistemic function, a thermostat is undoubtedly a constituent part of some epistemic tools whose components need to be maintained at a fixed temperature in order to perform their function. Other sorts of feedback control systems are also not uncommon as parts of sophisticated epistemic tools. tools do not possess epistemic agency). A simple thermostat is designed to achieve a goal: maintaining the constant specified temperature of a room. It contains a strip consisting of two different metals, typically steel and copper, which expand at different rates when they are heated. The different thermal expansions of the two metals force the bimetallic strip to bend one way when heated and the other way when cooled. The state of

bending of the strip thus contains information about the temperature of the room, which might be regarded as a very crude form of perceptual representation. This is because, on the basis of this information, the thermostat acts in a goal-directed fashion. It turns the furnace on when the room is colder than its specified set temperature and turns the furnace off when the room is warmer than its set temperature, thereby attaining its goal of regulating room temperature. In this sense, its behavior can be considered intentional. A purely physico-chemical description of the thermostat would tell us nothing about its function, why it is organized the way it is rather than some other way, or why some agent might have designed and built it. Such matters can only be discerned by taking what Dennett calls the design stance towards the device, from which its goal-directed organization and crude agency can be recognized (Dennett, 1987, pp. 37-42).

The robotic telescopes mentioned earlier are clear examples of a type of epistemic tools that are candidates for this sort of agency. Current robotic telescopes can autonomously perform functions that could be compared with the low level functions of the vertebrate visual system; simultaneously monitoring large numbers of celestial objects, detecting transient variations, selecting targets for detailed observation, conducting observations of them, and classifying them - all without direct human intervention (Vestrand et al., 2002; Vestrand et al., 2008; White et al., 2006).

Engineered artifacts possess intentionality, and can also possess agency but, crucially, both are derived from their designer and their user. A sentence of written text on paper, the reading of a thermometer, or a display on a computer screen contains semantic meaning, but only for an agent that understands it (Jacob, 2019; Nanay, 2006), and only when such agents wrote the text, designed the thermometer, or designed and programmed the computer. In this respect, however, epistemic and other tools are no different from the parts that make up a living organism, whose functions likewise can only be performed when they bear an appropriate relationship to the whole organism

The exact nature of the relationship between biological intentionality and natural selection is a matter of some controversy. Some see intentionality as a direct product of an organism's selection history (Dennett, 1994; Millikan, 1989), while others see biological intentionality as primordial, and a necessary precondition for evolution by natural selection (Davies, 2003; Walsh, 2002). of which they are a part, and whose functions are likewise the product of a long history of natural selection (Lewens, 2005, pp. 39-65; Millikan, 1984, pp. 17-38).

The firing of a neuron in the brain may perform a cognitive function. The firing of that same neuron removed from the brain and placed in a dish of nutrients does not. Clark and Chalmers (1998) have argued that an epistemic tool, when relied upon by an epistemic agent, can represent intentional content and perform a cognitive function for that agent, in much the same way that neurons can represent intentional content and perform a cognitive function when they are appropriately situated constituent parts of the agent's brain. The concept of distributed cognitive systems has been further developed by Clark (2001; 2007; 2008; 2010), Giere (2002; 2004; 2007; Giere \& Moffatt, 2003), and Palermos (2011; 2015). In a distributed cognitive system, cognitive processes extend beyond the mind of an individual epistemic agent to encompass an epistemic tool, or to other individual agents that together constitute a communal epistemic agent. In Clark's concept of the extended mind, it is the mind itself that is so extended.

When an employed method indicates that the behavior of some physical object or engineered system, under appropriate circumstances, contains semantic information that is an acceptable source of knowledge for answering a question about an object of inquiry, then that object or engineered system can be relied upon as an epistemic tool. Because it is thereby endowed with intentionality for the individual or communal epistemic agent that employs the requisite method, it can be deemed to participate in the intentionality of that epistemic agent. The 
team of one or more epistemic agents and an epistemic tool are a composed system (Wimsatt, 2006; 2007, pp. 274-312), and exhibit the complementary division of labour characteristic of such systems. An electron microscope possesses an ability that a human being does not. It can image structures too small to be perceived by the human eye. However, the microscope itself cannot semantically understand the images it produces. A human epistemic agent does possess this ability, along with the creative ability to formulate theories and the capacity to use reason, and the electron microscope images, to assess theories by an employed method. Together, the tool and the epistemic agent or agents have the emergent ability to produce scientific knowledge about tiny structures that neither could produce alone.

\section{Can Epistemic Tools be Epistemic Agents?}

We have so far seen that epistemic tools exhibit properties or behaviors that can be taken to possess intentional semantic content for an epistemic agent, such as the reading of a thermometer, the characters on a computer screen, or the content of a text. This is the case when the agent employs a method under which that property or behavior is an acceptable source of knowledge for answering some question. While such states depend on bearing an appropriate epistemic and physical relationship to an epistemic agent, this is not different in kind from the relationship that an individual epistemic agent bears to its neurons, which must also be appropriately situated in its brain in order for their states to contain intentional content and perform cognitive function (though in this latter case, unlike the case of the epistemic tool, the content is sub-symbolic). Given such similarities, a number of philosophers have argued that what we call epistemic agents and epistemic tools together form distributed cognitive systems (Giere, 2002; 2004; 2007; Giere \& Moffatt, 2003; Palermos, 2011; 2015), or even extended minds (Clark, 2001; 2007; 2008; 2010; Clark \& Chalmers, 1998). I have therefore proposed that epistemic tools can participate in the intentionality of epistemic agents. Beyond this, what is the relationship between epistemic tools and epistemic agents? Specifically, can epistemic tools participate in relationships of authority delegation? Can they themselves, as such a relationship requires, be regarded as a species of epistemic agent? I have shown that at least some epistemic tools, like the robotic telescope, do exhibit a crude sort of agency. Thus, I believe this question warrants careful analysis, in part, because it helps elucidate the distinctive roles of epistemic agents and epistemic tools. Nonetheless, I will argue, barring further progress in artificial intelligence, the answer is no.

Let us consider tools that produce output that is propositionally interpretable as scientific data, like the thermometer, gene sequencer, or robotic telescope. Scientific data, being propositions, are theories, and like all theories they require assessment as to whether they are acceptable sources of knowledge about the phenomenon in question. This is where the demand for semantic understanding contained in our definition of epistemic agency is salient. Let us begin with the simple case of the thermometer. Here, it should be obvious that the instrument itself is incapable of understanding semantically or assessing a theory such as "the temperature is currently $35^{\circ}$ Celsius". Instead, a thermometer user, with their capacities for semantic understanding and reason, will assess this theory. They might, for example, do so by an implicit method involving comparison with their thermal sensations, and with their prior expectations given the time of year and the weather conditions. If they feel chilly, it is mid-winter, and a snowstorm is in progress, they are likely to reject the theory that "the temperature is currently $35^{\circ}$ Celsius", and instead examine the thermometer for evidence of defect or malfunction. Theory assessment, including data assessment, requires the taking of epistemic stances intentionally, based on a semantic understanding of the epistemic elements in question and their alternatives. Since a simple symbolic epistemic tool like a thermometer clearly can't do this, its role seems fundamentally different from that of an epistemic agent to whom authority can be delegated.

While it may be obvious that a thermometer lacks the needed faculties for semantic understanding and reasoned choice, there are cases that require a bit more discussion. Consider, for instance, a system involving sophisticated computer software, like the gene sequencer, or even more notably, the robotic telescope. Suppose such a system was programmed to perform a series of tests, based on criteria derived from the employed method 
of data assessment, and to accept only data meeting those criteria? Could this be deemed a crude form of epistemic agency, and the system an expert to which authority could be delegated?

A specific example of such code shows why it does not. Since 1999, The Berkeley University Search for Extraterrestrial Intelligence (SETI) Research Center has operated one of the largest distributed computing projects in history, SETI@home. Using over six million personal computers over the first ten years of its history, the software searches radio astronomy data using five specific criteria expected for possible radio messages transmitted by extraterrestrial intelligence (Hipschman, 2019). The center maintains a database of sources of terrestrial radio interference with which software is used to further cull the list of potential candidate signals. Despite the sophistication of their software, and its ability to apply some of the concrete requirements of the employed data assessment method of SETI research by rote, the Berkeley researchers' stated protocol demonstrates that they clearly do not regard it as an epistemic agent or an appropriate object of authority delegation.

The researchers' plan anticipates that any candidate signal surviving rigorous automated tests would be carefully assessed by Berkeley radio astronomers and their peers by a variety of methods intended to rule out unanticipated hardware or software issues, novel forms of interference, or novel astrophysical phenomena. Ultimately, they anticipate that an assessment as to whether a candidate signal derives from extraterrestrial intelligence or from some other source would be made by the radio astronomy community as a whole (Hipschman, 2019). Lacking true semantic understanding, the computer software lacks the creative flexibility needed to draw on the more abstract requirements of the employed method of SETI research to deal with unanticipated problems or phenomena. Data regarding novel or unexpected phenomena are precisely those most relevant to scientific change.

Even for sophisticated computer software, semantic understanding rests with the epistemic agent who wrote the code, as does the expertise necessary to assess whether it is functioning properly and to accept the data it produces as a reliable source of knowledge about the phenomenon in question. Use of some machine learning techniques likewise requires a training set of examples selected by an agent, again based on the epistemic agent's semantic understanding of the task for the machine to be trained. As a result of training, the machine will acquire its own criteria for performing a task, but with no semantic understanding of those criteria. Any such understanding can only be attained by investigation of the trained machine by an epistemic agent (Vincent, 2016). Expertise, a necessary requirement for authority delegation, requires such an understanding.

Cognitive scientists, neuroscientists, and their philosophical allies seek a naturalistic account of semantic understanding in terms of the structure and function of brains, and the relationship between organisms and their environment (Morgan \& Piccinini, 2018; Neander, 2018). Semantic understanding of propositions by artificial systems is likewise today regarded as a grand challenge by computer scientists (Embley, 2004). But while such technologies may be on the horizon, they have not yet, to any significant degree, been achieved. In the current state of artificial intelligence, even sophisticated data producing tools are not epistemic agents, to whom authority might be delegated.

Not all epistemic tools whose symbolic output can be interpreted propositionally produce new scientific data. Consider again a Galenic text relied upon hundreds of years after Galen's death, or a modern scientific paper written by someone whom the reader might never have met or interacted with. A modern scientific paper typically contains a methods section, in which the observational or experimental methods used to obtain the results are carefully described. Does this constitute the paper justifying its contents in terms of a method? The problem, of course, is that the methods were not employed by the paper itself. They were employed by the individual or communal agent who performed the research, and the paper merely serves as a means to communicate this fact. Should new questions arise concerning the validity of the data, it is the authors, and not the paper itself, who must respond. Once an author, like Galen, has died, neither the text nor its author can respond to novel questions or challenges. Only the living can interpret the works of the dead, based on their semantic understanding of those works. Even when certain texts, such as the Bible, are deemed to have an infallible author, there are still communities that engage in debates over matters of interpretation, and proper methods for doing so. It is to these 
communities, and not to the text itself, to which authority may be delegated. The argument that no historical or present-day epistemic tools can be regarded as epistemic agents may be summarized as follows:

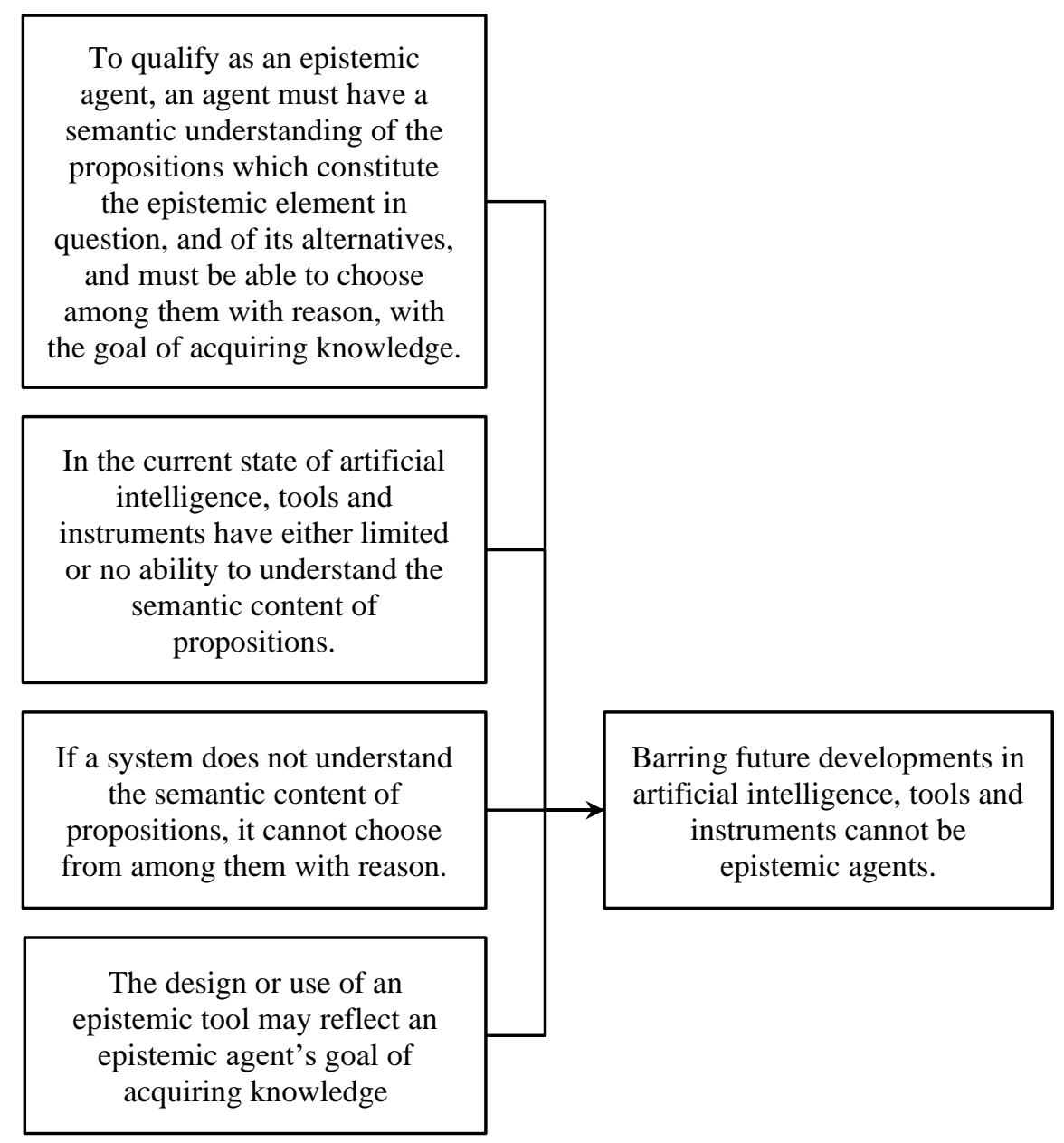

From this it follows that epistemic tools cannot be the subject of authority delegation. Because they lack the capacity to semantically understand propositions, epistemic tools cannot assess theories and are therefore not the sort of thing to which authority can be delegated. Therefore, epistemic tools must be accorded a distinctive place in the scientonomic ontology. To understand this distinctive role, we must return to our earlier discussion of the relationship between theories, employed methods, and epistemic tools.

\section{Epistemic Tools and Employed Methods}

Barseghyan (2015, pp. 7-8) has noted that employed methods of theory assessment form a hierarchy ranging from abstract and general (for example, the hypothetico-deductive method), to concrete and specific (for example, that a cell count obtained using flow cytometry is acceptable). The more concrete portions of the method hierarchy tell us what procedures ought to be followed, and what actions ought to be taken for an epistemic tool to serve as an acceptable source of knowledge for answering some question. The formulation and assessment of theories concerning epistemic tools allows for the deduction of methods specifying how those tools ought to be designed and the proper procedures that ought to be followed to collect data with them. Such methods specify how data (which in scientonomic terms are theories requiring assessment) ought to be assessed. This activity is a central component of most scientific research. We can best illustrate this with an example drawn from the practice of radio astronomy.

The giant radio telescope dish at the Parkes Observatory in Australia has been heralded by the Australian Broadcasting Corporation as "the most successful scientific instrument ever built in Australia" and has been used 
in a number of projects by NASA (Robertson, 2010). To succeed in its function of detecting faint radio emissions from deep space, the design of this epistemic tool must be in accordance with methods or norms derived from a variety of theories describing the properties and behavior of radio waves. For example, to detect faint radio emissions from deep space, the telescope takes the form of a 64 meter parabolic dish which reflects radio waves and thereby concentrates radio waves falling at any point of the dish onto a receiver located at the focus of the parabola (Zeilik \& Gregory, 1998, pp. 184-187).

In 2007, a Parkes astronomer examining archived data found something very strange: a five millisecond long intense burst of radio waves from an unknown source. These fast radio bursts were subsequently detected by other telescopes - an important criterion for the acceptance of the celestial nature of a radio source in astronomy (Gibney, 2016). By a variety of criteria, they were taken to originate from sources outside our galaxy. They were shown to be fairly common, with one flashing somewhere in the sky every ten seconds. They are of great interest because they are novel and lack an explanation in terms of known astrophysical theories (Gibney, 2016).

Human-made and natural interference, from a variety of sources, is a frequent problem for radio astronomers, requiring them to make these interference sources a topic of inquiry. By formulating theories about such interference sources, astronomers can deduce methods of data assessment from them, so as to only accept data derived from astronomical sources and reject data derived from interference. One set of Parkes observations cast a shadow of doubt over the theories and methods used to classify the mysterious fast radio bursts as celestial phenomena. On twenty-five occasions since 1998, radio astronomers at Parkes detected a particular sort of fast radio burst, perytons. The signals seemed to exhibit the dispersion caused by passage through cold plasma in deep space. Under the method employed at the time, this was taken as a key indicator of extragalactic origin. But, unlike other fast radio bursts, perytons were detectable over a wide field of view. Also, under the method employed at the time, this was taken to indicate that they did not come from a distant point in space, but rather might be a local terrestrial phenomenon. This apparent contradiction might impugn the method by which all fast radio bursts were assessed to be of astronomical origin, including those detected by other telescopes. A theory of the signal's origin might allow one to deduce a new method for assessing data so as to better rule out nonastronomical signals. Formulating such a theory required careful sleuthing by astronomers and engineers and the supercomputer facilities of Swinburne University of Technology (Burke-Spolaor et al., 2010; Gibney, 2016; Petroff et al., 2015).

It was theorized that lighting or other terrestrial atmospheric phenomena were the source of perytons (Dodin \& Fisch, 2014; Katz, 2014). However, all twenty-five observed peryton bursts exhibited an additional suspicious feature; they all occurred during office hours on weekdays, and, most typically, at lunchtime. This behavior is, of course, not characteristic of lightning storms. When a new radio frequency interference monitor was installed at the observatory, peryton emissions at $1.4 \mathrm{GHz}$ were found always to correspond with another emission around 2.3 to $2.5 \mathrm{GHz}$, a frequency emitted by a number of commercial devices, including microwave ovens. Careful analysis showed that perytons occurred when a microwave oven used by observatory staff to heat their lunch was opened prematurely and released a burst of microwaves, and the radio telescope was pointed in the appropriate direction (Petroff et al., 2015; Richter, 2016). In total, five scientific papers were published with perytons in the title, representing the work of twenty-two Australian and American co-authors. As a result of this research a new theory became accepted, namely that perytons were due to interference from microwave ovens. From this new theory, new norms or methods followed, aimed at preventing astronomers from confusing microwave ovens with astronomical phenomena in the future. The troubleshooting research showed that perytons clearly differed substantially from other fast radio bursts, which are still assessed as astronomical and originating outside our galaxy. They remain a mystery of increasing research interest to astronomers.

The example demonstrates that an important facet of scientific research has to do with theories from which methods can be deduced for assessing the acceptability of data obtained by means of an epistemic tool. Concrete methods that are deduced from theories allow the assessment of the data and the formulation of normative procedures aimed at the collection of acceptable data. In the example, the epistemic agents in question are the researchers and research teams who rely on the Parkes telescope as a source of astronomical data, and the highly 
skilled engineers responsible for its design and successful operation. These researchers have become experts in the instrument's proper use, and the trustworthiness of their data as a source of astronomical knowledge rests on their expertise. It is this communal agent, consisting of the telescope itself, a research team, and engineers, to which the broader astronomical community can delegate authority regarding the data obtained by the telescope as a source of astronomical knowledge.

\section{Tool Reliance}

We are now in a position to introduce the concept of tool reliance to denote the relationship between epistemic agents and epistemic tools. Due to their goal-directed organization and intentional content, epistemic tools can participate in the intentionality of an epistemic agent and can thus be regarded as a constituent part of the latter. We have rejected the idea that epistemic tools are a subtype of epistemic agent. Consequently, we rejected the idea that tools can stand in relations of authority delegation to epistemic agents. We have also seen that the role of epistemic tools in scientific research is prescribed by employed methods, and that the theories from which such methods can be derived are often an active topic of scientific research, particularly when an anomaly or problem is discovered. That being the case, authority can be delegated to an epistemic agent with expertise in theories and methods prescribing the use and proper function of the tool in question, and the assessment of data obtained from the tool. Such an expert epistemic agent can determine, for example, whether data from a radio telescope derives from an astronomical source and should be accepted as a source of knowledge about that source, or from a microwave oven and should not be accepted as a source of astronomical knowledge.

While epistemic tools cannot be delegated any authority, then can clearly be relied upon. An epistemic agent is said to rely on an epistemic tool when there is a procedure through which the tool can provide an acceptable source of knowledge for answering some question under the employed method of that agent:

\section{Tool Reliance $\equiv$}

An epistemic agent is said to rely on an epistemic tool iff there is a procedure through which the tool can provide an acceptable source of knowledge for answering some question under the employed method of that agent.

To indicate the relationships of tool reliance on scientonomic diagrams, I suggest appropriating the standard UML ball-and-socket connector, where the ball indicates the functionality provided by the respective tool, and the socket indicates that the epistemic agent requires that functionality:

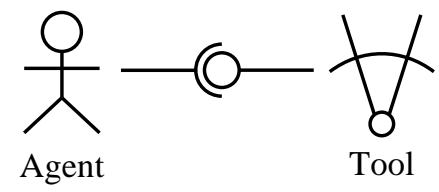

Note that tool reliance, like authority delegation, is reducible to the theories and methods of the epistemic agent that relies on the tool.

\section{An Example: The Hubble Space Telescope Community}

Having proposed definitions of epistemic agent, epistemic tool, tool reliance, and authority delegation, and outlined a view of the relationship between epistemic agents and epistemic tools in terms of the prescriptions of employed methods and of distributed cognitive systems, I am now in a position to illustrate the application of this new conceptual framework to the analysis of a very sophisticated system - the scientific and engineering communities associated with the National Aeronautics and Space Administration (NASA)'s Hubble Space 
Telescope (HST) project. This project has been discussed previously in the context of distributed cognition (Giere, 2004; 2007; Vaesen, 2011). What is attempted here is nothing more than a rough sketch for the purpose of illustration only, using information available on NASA websites and in the publications of Hubble astronomers. A full explication of this complex set of epistemic agents and tools, and their relationships of reliance and delegation to one another, is far beyond the scope of this paper.

What we will call the HST community is a communal epistemic agent, which consists of other epistemic agents and their epistemic tools, all sharing an intentionality to gain knowledge of astronomical objects by means relying on the Hubble Space telescope. The communal agent includes those scientists, engineers, technicians, and managers who are or have been directly involved in the HST project as employees of NASA, its contractors, or of the many universities whose researchers rely on the HST for their research. This communal epistemic agent includes many other communal epistemic agents, each with its own distinctive and specialized role in the overall community, linked by relationships of authority delegation. Thousands of astronomical research teams, each with their own specific epistemic goals, have relied on Hubble for their research since its launch in 1990 (Hubble Site, 2019; NASA, 2019). The epistemic tools relied upon include the Hubble spacecraft itself, a network of NASA tracking and data relay satellites that allow the spacecraft to communicate with the ground (NASA, 2017), the space shuttle - which launched the HST and conducted four missions to service and upgrade it - and a vast array of computers and other equipment.

We will focus on one particular HST research group - that of the $H_{0}$ key project. This project was an international collaboration of 15 astronomers, from the United States, Canada, the United Kingdom, and Australia. A constituent part of the HST community, this research group can itself be considered a communal epistemic agent playing a specialized role in the overall HST community. The team accomplished a core research objective of the HST project by making a new estimate of a cosmological parameter called the Hubble constant $\left(H_{0}\right)$. The

The Hubble constant describes the expansion of the universe by specifying the relationship between a galaxy's rate of recession, and its distance from Earth. It thereby allows the age and size of the universe to be estimated. Like the telescope itself, the constant is named for astronomer Edwin Hubble, who discovered the relationship and the expansion of the universe.

accept that atmospheric distortion due to turbulent air limits the resolving power of telescopes and that it is therefore advantageous to conduct astronomical observations from a vantage point above the Earth's atmosphere (Spitzer Jr, 1979), and thus space-based telescopes are prescribed for answering some questions. Among many other objectives, accepted theories showed that such a telescope was specifically useful for making an improved estimate of $H_{0}$. Determining the Hubble constant requires a means of measuring the distance to a far-off galaxy. Astronomers estimate the relative distances to galaxies by several methods, but they all require calibration with a set of absolute distance measurements. One of the few means of measuring such distances involves a type of star called a Cepheid variable. These stars change in brightness over a cycle of days to weeks, and the duration of the cycle is known to be related to the star's absolute brightness. So, if the star's variation period and apparent brightness in the sky can be measured, its distance from Earth can be calculated (Peebles, 1993). The high resolving power of the HST made it possible to detect such stars in galaxies as far as twenty megaparsecs (Mpc) from Earth. The lack of atmospheric distortion made it possible to conduct very precise photometric measurements of their brightness. By doing so, it could greatly improve our estimate of $H_{0}$ over what was possible with ground-based telescopes. The goal of making this measurement and answering this question became a key factor in prescribing the design of the Hubble telescope.

Note, in all of this, that an extensive body of theory comes into play when prescriptions are being derived regarding epistemic tools and strategies for their proper use, given the goal of answering a question. Other teams of astronomers use Hubble whenever the theories they accept can be used to derive methods that prescribe it as the instrument best suited to their needs. The diagram gives a highly simplified account of the relevant theory and method accepted by the $H_{0}$ key group mandating their reliance on the Hubble Space Telescope: 


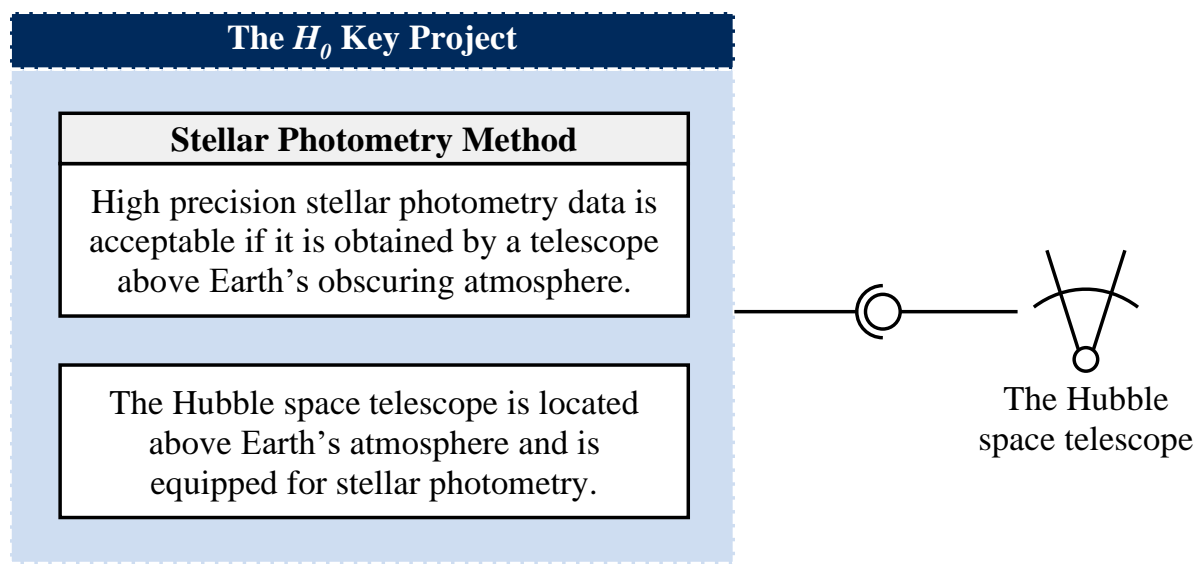

The $H_{0}$ key project garnered its opportunity to become part of the HST community by way of the Space Telescope Science Institute (STSI) at Johns Hopkins University in Baltimore, which is in charge of science operations of the telescope for NASA (STSI, 2019). Each year, the institute issues a call for proposals from astronomers, and about 200 of the 1000 proposals submitted are selected by peer review. STSI delegates authority for the conduct of selected research projects to the specific research teams it selects, such as the $H_{0}$ key project. As of 2010, over 10,000 scientific papers have been published based on Hubble results. The $H_{0}$ key project, in turn, delegated authority for the direct conduct of astronomical observations with Hubble to two other communal epistemic agents: the STSI and the Space Telescope Operations Control Center (STOCC) at NASA's Goddard Space Flight Center in Greenbelt, Maryland. STSI is responsible for scheduling astronomical observations with Hubble, calibrating the received data, and retaining an archive of the datasets (NASA, 2018). These activities, no doubt, involve extensive reliance on computers.

STOCC is the mission control center for the HST. It is a communal epistemic agent consisting of engineers responsible for operating and maintaining the Hubble spacecraft itself. At the time of the $H_{0}$ key project, in the 1990's, a team of four engineers were on duty in the Mission Operations Room around the clock, each with their own domain of specialized expertise about the spacecraft's systems. Note the pervasiveness of organized division of labour - a hallmark of a composed system - and therefore of collective intentionality. The engineers executed the required procedures to acquire communications with the telescope, manage Hubble's science and engineering data recorders, and load Hubble's computers with command sequences. They monitored telemetry from the spacecraft and reported problems to the appropriate subsystem engineers. They were backed by a larger team of roughly ninety engineers, technicians, and managers, and support personnel with their own specialized roles. Commands for astronomical observations are coded and uploaded to the telescope, and results downlinked (i.e. transmitted to the ground) on a daily basis (NASA, 2018; 2019).

In 2011, thanks to progress in robotic telescope technology, Hubble flight operations were automated. STOCC engineering personnel now rely on computer software for the routine operation of the telescope and focus on special operations and various tests. The automated system alerts them to any problems requiring the flexible problem-solving abilities of epistemic agents, which again demonstrates the current limited agency of automated systems. The engineers are aided in their troubleshooting and operations work by a complete simulator of the Hubble spacecraft called the Vehicle Electrical System Test facility (NASA, 2018). In their operation of the Hubble spacecraft, the engineers are guided by technological theories. The role of technological knowledge in the scientific mosaic has recently been discussed by Mirkin (2018).

Launched in 1990 and upgraded and serviced by subsequent space shuttle missions, the Hubble spacecraft consists of a number of specialized systems designed to work together in an integrated fashion, realizing a clear division of labour. The HST was designed by teams of engineers, each with their own specialty in areas such as optics, communication, guidance and control, astrodynamics, and many others. Its systems are too complex for any one individual to fully understand. A 2.4-meter diameter mirror collects light, which is directed by smaller 
mirrors onto the telescope's electronic sensors, which transduce light energy into electrical impulses which become digital data. A pointing system uses torque producing motorized flywheels to stabilize and point the telescope. Computers use input from gyroscopes and sensors to control the system. Solar panels supply the pointing system and other systems with the needed electrical power and must point at the sun while the telescope points at its targets. Two main computers control a whole network of others (Hubble Site, 2019; NASA, 2019). The telescope itself is a constituent part of a larger system, each of whose specialized parts make a distinctive contribution to the function of the whole. From the telescope, data is first transmitted to a network of NASA communications satellites, and downlinked to a NASA ground station in New Mexico. From there, it is relayed via commercial satellites to STOCC. The STOCC community delegates authority for the operation of NASA's communications satellites to another community of engineers, also headquartered at the Goddard Space Flight Center (NASA, 2017). When a team of astronomers make observations with the HST, they are delegating authority to multiple communal epistemic agents. These communal agents rely on the telescope itself, as well as a vast array of other epistemic tools necessary for its operation and control.

By way of its authority delegation to the STSI and STOCC communities, the $H_{0}$ project community obtained measurements of Cepheid variables in eighteen spiral galaxies between three and twenty-five Mpc from Earth. Repeated observations of each of the galaxies under study had to be made, and Cepheid variables were identified in each galaxy based on their variations in brightness over time in images captured by the telescope. From as few as seven to as many as ninety-eight of the stars per galaxy were used. To calculate the distance to each star, both its brightness and period of variation had to be carefully determined.

While the $H_{0}$ project community delegated authority for the technological aspects of proper data acquisition to the STSI and STOCC communities, they were centrally involved in assessing the trustworthiness of the data. Accurate measurement of astronomical light intensities, or photometry, is a demanding challenge which requires carefully calibrated instruments. Devising and performing these calibrations were essential to the astronomers' method. The $H_{0}$ project community carried out their own calibration of the light sensing ability of two Hubble instruments, alongside parallel efforts by the teams that built these instruments and by the Space Telescope Science Institute, engaging in mutual authority delegation with one another (Overgaard \& Loiselle, 2016). Various imperfections of the charge-coupled device (CCD) array that sense light were found to impose limits on the accuracy of the measurements. A calibration developed by a member of the team, P. B. Stetson (1998), was adopted. Note the role of authority delegation to individuals in this research group.

To guard against systematic errors in their photometric measurements, a double blind data analysis process

The term double blind was used by the astronomers with a somewhat different meaning than its more traditional usage in biomedical research. It simply means that the two analysis groups were unaware of each other's results until after the separate analyses were completed. was used in which two separate teams within the $H_{0}$ key project analyzed brightness data using different software packages, with different correction strategies, and the results were only compared at the end (Freedman et al., 2001; Freedman et al., 1994), another example of mutual authority delegation. As for the Parkes radio telescope, theories related to the proper function of the instrument, from which methods of assessing the trustworthiness of its data could be deduced, were a major focus of effort by epistemic agents. The extensive division of epistemic labor provides clear evidence that this is composed system, with different epistemic agents contributing to the overall result in their own distinctive ways.

The Cepheid variable distances that the team could measure were too nearby to be useful in directly determining $H_{0}$. Instead, they were used to calibrate five other relative distance determination methods. To do this, the $H_{0}$ key project community delegated authority regarding those methods to other communities of astronomers. These other communities of astronomers made their own measurements using alternative groundbased or spacecraft observatories and their associated engineering and operations communities, and a variety of assumptions and calibrations. In the end, the $H_{0}$ key project community obtained a value of $H_{0}=72(\mathrm{~km} / \mathrm{sec}) / \mathrm{Mpc}$ and an estimate of 13 billion years for the age of the universe. They saw the rough agreement of the multiple independent methods that they used as reasons for assessing their estimate as accurate (Freedman et al., 2001). This finding was clearly the result of a whole system of interacting communal epistemic agents, none of which 
were capable of producing it alone. The role of the various agents and tools were different and complementary. Reliance on the Hubble telescope formed part of the employed method of the $H_{0}$ key project community, with that method derived from theories about atmospheric distortion and telescope resolving power, and the finer points of astronomical photometry. The community assessed their Hubble data as trustworthy, based on careful efforts to properly characterize and calibrate Hubble's photometer. They assessed their new estimate of the Hubble constant to be accurate because of agreement between multiple findings from independent lines of reasoning. A portion of the set of relationships making up the Hubble community may be diagrammed as follows:

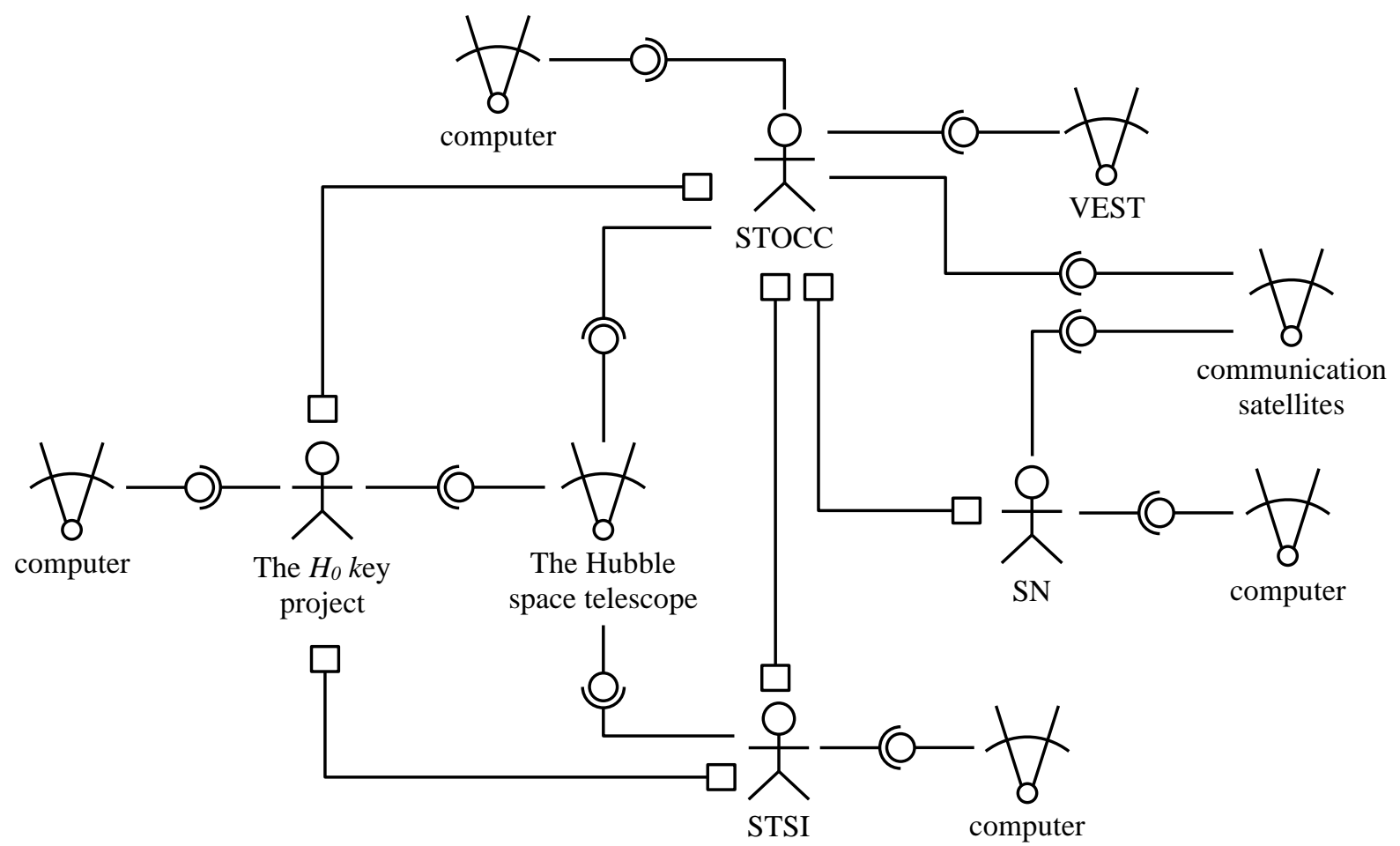

\section{Conclusion}

This paper has argued for several revisions to the scientonomic ontology. I have argued that an epistemic agent is an entity capable of taking epistemic stances towards epistemic elements, with reason, based on a semantic understanding of the elements and their available alternatives, and with the goal of producing knowledge. Both individuals and communities can be epistemic agents. Epistemic agents can engage in relationships of authority delegation. A physical object or system is an epistemic tool for an epistemic agent when there is a procedure by which the tool can provide an acceptable source of knowledge for answering some question under the employed method of that agent. Under an employed method, some behavior or property of an epistemic tool can contain intentional content about the topic of inquiry. Epistemic tools can thus, in a crude sense, share in the collective intentionality of a communal epistemic agent, or the intentionality of an individual epistemic agent. Such systems are composed distributed cognitive systems, in which each constituent makes a distinctive specialized cognitive contribution to the function of the communal agent as a whole. Currently, only human beings, individually or communally, possess the faculties necessary to qualify as epistemic agents. In the current state of artificial intelligence, epistemic tools are incapable of semantically understanding propositions. Therefore, they cannot employ a method to assess a theory in relation to its alternatives. Thus, they cannot fit the definition of epistemic agency adopted here and cannot be subjects of authority delegation. Authority may be delegated to the communal or individual epistemic agent relying on an epistemic tool, when that agent demonstrates expert ability to assess the data it produces as acceptable. To describe the role of epistemic tools in relation to epistemic agents that make 
use of them, I have introduced the relationship of tool reliance. An epistemic agent is said to rely on an epistemic tool when there is a procedure through which a tool can provide an acceptable source of knowledge for answering some question under the employed method of that agent. Both authority delegation and tool reliance are reducible to theories and methods.

\section{Acknowledgements}

The author wishes to thank Terese Pierre for an earlier paper which inspired the writing of this one, and Nick Overgaard for valuable comments on an earlier draft of this paper.

\section{Suggested Modifications}

I suggest the following modifications to scientonomic theory:

\section{[Sciento-2019-0014]}

Accept the following definition of epistemic agent:

- Epistemic Agent $\equiv$ an agent capable of taking epistemic stances towards epistemic elements.

\section{Epistemic Agent $\equiv$}

An agent capable of taking epistemic stances towards epistemic elements.

\section{[Sciento-2019-0015]}

Accept that there are two types of epistemic agents - individual and communal.

Also accept the following question as a legitimate topic of scientonomic inquiry:

- Applicability of the Laws of Scientific Change to Individuals: do the scientonomic laws apply to individual epistemic agents?

\section{[Sciento-2019-0016]}

Accept the term epistemic tool, with the following definition:

- Epistemic Tool $\equiv$ a physical object or system is an epistemic tool for an epistemic agent, when there is a procedure by which the tool can provide an acceptable source of knowledge for answering some question under the employed method of that agent.

\section{Epistemic Tool $\equiv$}

A physical object or system is an epistemic tool for an epistemic agent iff there is a procedure by which the tool can provide an acceptable source of knowledge for answering some question under the employed method of that agent.

Also accept that the following symbol is to be used in scientonomic diagrams to depict epistemic tools:

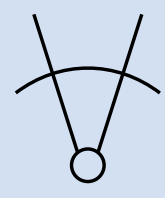




\section{[Sciento-2019-0017]}

Accept the following definition of authority delegation, which generalizes the currently accepted definition to apply to all epistemic agents:

- Authority Delegation $\equiv$ epistemic agent A is said to be delegating authority over question $x$ to epistemic agent B iff (1) agent A accepts that agent B is an expert on question $x$ and (2) agent A will accept a theory answering question $x$ if agent B says so.

\begin{tabular}{|c|}
\hline Authority Delegation $\equiv$ \\
\hline Epistemic agent A is said to be delegating authority over \\
question $x$ to epistemic agent B iff (1) agent A accepts that \\
agent B is an expert on question $x$ and (2) agent A will \\
accept a theory answering question $x$ if agent B says so. \\
\hline
\end{tabular}

Also accept the following redefinitions of subtypes of authority delegation, including mutual authority delegation, one-sided authority delegation, singular authority delegation, multiple authority delegation, hierarchical authority delegation, and non-hierarchical authority delegation:

- Mutual Authority Delegation $\equiv$ epistemic agents A and B are said to be in a relationship of mutual authority delegation iff $\mathrm{A}$ delegates authority over question $x$ to $\mathrm{B}$, and $\mathrm{B}$ delegates authority over question $y$ to $\mathrm{A}$.

- One-Sided Authority Delegation $\equiv$ epistemic agents A and B are said to be in a relationship of one-sided authority delegation iff A delegates authority over question $x$ to B, but B doesn't delegate any authority to $\mathrm{A}$.

\section{Mutual Authority Delegation $\equiv$}

Epistemic agents A and B are said to be in a relationship of mutual authority delegation iff A delegates authority over question $x$ to $\mathrm{B}$, and $\mathrm{B}$ delegates authority over question $y$ to $\mathrm{A}$.

\section{One-Sided Authority Delegation $\equiv$}

Epistemic agents $\mathrm{A}$ and $\mathrm{B}$ are said to be in a relationship of one-sided authority delegation iff A delegates authority over question $x$ to $\mathrm{B}$, but B doesn't delegate any authority to A.

- Singular Authority Delegation $\equiv$ epistemic agent A is said to engage in a relationship of singular authority delegation over question $x$ iff A delegates authority over question $x$ to exactly one epistemic agent.

- Multiple Authority Delegation $\equiv$ epistemic agent A is said to engage in a relationship of multiple authority delegation over question $x$ iff A delegates authority over question $x$ to more than one epistemic agent.

\section{Singular Authority Delegation $\equiv$}

Epistemic agent $\mathrm{A}$ is said to engage in a relationship of singular authority delegation over question $x$ iff A delegates authority over question $x$ to exactly one epistemic agent.

\section{Multiple Authority Delegation $\equiv$}

Epistemic agent $\mathrm{A}$ is said to engage in a relationship of multiple authority delegation over question $x$ iff A delegates authority over question $x$ to more than one epistemic agent.

- Hierarchical Authority Delegation $\equiv$ a sub-type of multiple authority delegation where different epistemic agents are delegated different degrees of authority over question $x$.

- Non-Hierarchical Authority Delegation $\equiv$ a sub-type of multiple authority delegation where different epistemic agents are delegated the same degree of authority over question $x$.

\section{Hierarchical Authority Delegation $\equiv$}

A sub-type of multiple authority delegation where different epistemic agents are delegated different degrees of authority over question $x$.

\section{Non-Hierarchical Authority Delegation $\equiv$}

A sub-type of multiple authority delegation where different epistemic agents are delegated the same degree of authority over question $x$. 


\section{[Sciento-2019-0018]}

Accept that the relationship of tool reliance can obtain between epistemic agents and epistemic tools.

Accept the following definition of tool reliance:

- Tool Reliance $\equiv$ an epistemic agent is said to rely on an epistemic tool when there is a procedure through which the tool can provide an acceptable source of knowledge for answering some question under the employed method of that agent.

\begin{tabular}{|c|}
\hline Tool Reliance $\equiv$ \\
\hline An epistemic agent is said to rely on an epistemic \\
tool iff there is a procedure through which the tool \\
can provide an acceptable source of knowledge \\
for answering some question under the employed \\
method of that agent. \\
\hline
\end{tabular}

Also accept that the following symbol is to be used in scientonomic diagrams to depict the relation of tool reliance:

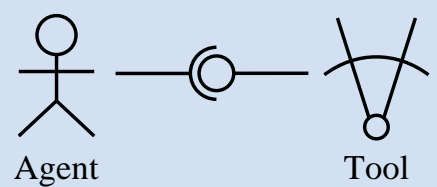

\section{Bibliography}

Ariew, A.; Cummins, R.; \& Perlman, M. (Eds.) (2002). Functions: New Essays in the Philosophy of Psychology and Biology. Oxford University Press.

Bakos, G.; Lazar, J.; Papp, I.; Sari, P.; \& Green, E. M. (2002). System Description and First Light Curves of the Hungarian Automated Telescope, an Autonomous Observatory for Variability Search. Publications of the Astronomical Society of the Pacific 114(799), pp. 974-987.

Barnes, B. (2013). The Elements of Social Theory. Routledge.

Barseghyan, H. (2015). The Laws of Scientific Change. Springer.

Barseghyan, H. (2018). Redrafting the Ontology of Scientific Change. Scientonomy 2, pp. 13-38.

Bechtel, W. (2008). Mental Mechanisms: Philosophical Perspectives on Cognitive Neuroscience. Lawrence Erlbaum Associates.

Bentley-Condit, V. K. \& Smith, E. O. (2010). Animal Tool Use: Current Definitions and an Updated Comprehensive Catalog. Behaviour 147, pp. 185-221.

Breuer, T.; Ndoundou-Hockemba, M.; \& Fishlock, V. (2005). First Observation of Tool Use in Wild Gorillas. PLoS Biology 3(11), article e380.

Buchwald, J. Z. (Ed.) (1995). Scientific Practice: Theories and Stories of Doing Physics. University of Chicago Press. Burke-Spolaor, S.; Bailes, M.; Ekers, R.; Macquart, J.-P.; \& Crawford III, F. (2010). Radio Bursts with Extragalactic Spectral Characteristics Show Terrestrial Origins. The Astrophysical Journal 727(1), article 18.

Carruthers, P.; Stitch, S.; \& Siegal, M. (Eds.). (2002). The Cognitive Basis of Science. Cambridge University Press.

Cartwright, N. \& Montuschi, E. (Eds.) (2014). Philosophy of Social Science: An Introduction. Oxford University Press.

Churchland, P. M. (1981). Eliminative Materialism and the Propositional Attitudes. The Journal of Philosophy 78(2), pp. 67-90.

Clark, A. (1998). Being There: Putting Brain, Body, and World Together Again. MIT press.

Clark, A. (2001). Natural-Born Cyborgs? Springer.

Clark, A. (2007). Curing Cognitive Hiccups: A Defense of the Extended Mind. The Journal of Philosophy 104(4), pp. 163192.

Clark, A. (2008). Supersizing the Mind: Embodiment, Action, and Cognitive Extension. Oxford University Press.

Clark, A. (2010). Memento's Revenge: The Extended Mind, Extended. In Menary (Ed.) (2010), pp. 43-66.

Clark, A. \& Chalmers, D. J. (1998). The Extended Mind. Analysis 65, pp. 1-11. 
Corradini, A. \& O’Connor, T. (Eds.) (2010). Emergence in Science and Philosophy. Routledge.

Davies, P. S. (2003). Norms of Nature: Naturalism and the Nature of Functions. The MIT Press.

Deacon, T. W. (2012). Incomplete Nature: How Mind Emerged from Matter. WW Norton \& Company.

Denneau, L.; Jedicke, R.; Grav, T.; Granvik, M.; Kubica, J.; Milani, A.; \& Pierfederici, F. (2013). The Pan-STARRS

Moving Object Processing System. Publications of the Astronomical Society of the Pacific 125(926), pp. 357-395.

Dennett, D. C. (1971). Intentional Systems. The Journal of Philosophy 68(4), pp. 87-106.

Dennett, D. C. (1983). Intentional Systems in Cognitive Ethology: The "Panglossian Paradigm" Defended. Behavioral and Brain Sciences 6(3), pp. 343-390.

Dennett, D. C. (1984). Elbow Room: The Varieties of Free Will Worth Wanting. MIT Press.

Dennett, D. C. (1987). The Intentional Stance. MIT Press.

Dennett, D. C. (1991). Real Patterns. The Journal of Philosophy 88(1), pp. 27-51.

Dennett, D. C. (1994). The Myth of Original Intentionality. In Dietrich (Ed.) (1994), pp. 91-107.

Dennett, D. C. (2003). Freedom Evolves. Penguin Putnam Inc.

Dietrich, E. (Ed.) (1994). Thinking Computers and Virtual Persons: Essays on the Intentionality of Machines Hardcover. Academic Press.

Dodin, I. \& Fisch, N. (2014). Are Perytons Signatures of Ball Lightning? The Astrophysical Journal 794(2), article 98.

Donald, M. (1991). Origins of the Modern Mind: Three Stages in the Evolution of Culture and Cognition. Harvard University Press.

Drake, A.; Djorgovski, S.; Mahabal, A.; Prieto, J.; Beshore, E.; Graham, M.; Catalan, M.; Larson, S.; Christensen, E.; Donalek, C.; \& Williams, R. (2011). The Catalina Real-Time Transient Survey. In Griffin, Hanisch, \& Seaman (Eds.) (2011), pp. 306-308.

Dretske, F. I. (1981). Knowledge and the Flow of Information. CSLI Publications.

Dretske, F. I. (1983). Precis of Knowledge and the Flow of Information. The Behavioral and Brain Sciences 6, pp. 55-90.

Embley, D. W. (2004). Toward Semantic Understanding: An Approach Based on Information Extraction Ontologies. In Schewe \& Williams (Eds.) (2004), pp. 3-12.

Fitch, W. T. (2008). Nano-Intentionality: A Defense of Intrinsic Intentionality. Biology \& Philosophy 23(2), pp. 157-177. Freedman, W. L.; Madore, B. F.; Gibson, B. K.; Ferrarese, L.; Kelson, D. D.; Sakai, S.; Mould, J. R.; Kennicutt, Jr. R. C; Ford, H. C.; Graham, J. A.; Huchra J. P.; Hughes, S. M. G.; Illingworth, G. D.; Macri, L. M.; \& Stetson, P. B. (2001). Final Results from the Hubble Space Telescope Key Project to Measure the Hubble Constant Based on Observations with the NASA/ESA Hubble Space Telescope, Obtained at the Space Telescope Science Institute, which is Operated by AURA, Inc., under NASA contract NAS5-26555. The Astrophysical Journal 553(1), pp. 47-72.

Freedman, W.L.; Madore, B.F.; Mould, J.R.; Hill, R.; Ferrarese, L.; Kennicutt, R. C. Jr.; Saha, A.; Stetson, P.B.; Graham, J.A.; Ford, H.; Hoessel, J.G.; Huchra, J.; Hughes, S.M.; Illingworth, G.D. (1994). Distance to the Virgo Cluster Galaxy M100 from Hubble Space Telescope Observations of Cepheids. Nature 371(6500), pp. 757-762.

Fulda, F. C. (2016). Natural Agency: An Ecological Approach. Unpublished Doctoral Dissertation, University of Toronto, Toronto, ON, Canada.

Fulda, F. C. (2017). Natural Agency: The Case of Bacterial Cognition. Journal of the American Philosophical Association 3(1), pp. 69-90.

Galison, P. (1987). How Experiments End. University of Chicago Press.

Galison, P. (1995). Context and Constraints. In Buchwald (Ed.) (1995), pp. 13-41.

Galison, P. (1997). Image and Logic: A Material Culture of Microphysics. University of Chicago Press.

Gibney, E. (2016). Mystery in the Heavens. Nature 534 (7609), pp. 610-612.

Gibson, J. J. (1967). New Reasons for Realism. Synthese 17(1), pp. 162-172.

Gibson, J. J. (1979). The Ecological Approach to Visual Perception. Houghton-Mifflin.

Gibson, J. J. (2002). A Theory of Direct Visual Perception. In Noë \& Thompson (Eds.) (2002), pp. 77-91.

Giere, R. N. (2002). Scientific Cognition as Distributed Cognition. In Carruthers, Stitch, \& Siegal (Eds.) (2002), pp. 285299.

Giere, R. N. (2004). The Problem of Agency in Scientific Distributed Cognitive Systems. Journal of Cognition and Culture 4(3), pp. 759-774.

Giere, R. N. (2007). Distributed Cognition Without Distributed Knowing. Social Epistemology 21(3), pp. 313-320.

Giere, R. N. \& Moffatt, B. (2003). Distributed Cognition: Where the Cognitive and the Social Merge. Social Studies of Science 33(2), pp. 301-310. 
Gillon, M.; Jehin, E.; Magain, P.; Chantry, V.; Hutsemékers, D.; Manfroid, J.; Queloz, D.; \& Udry, S. (2011). TRAPPIST: A Robotic Telescope Dedicated to the Study of Planetary Systems. EPJ Web of Conferences 11, 06002.

Godfrey-Smith, P. (2006). Mental Representation, Naturalism, and Teleosemantics. In Macdonald \& Papineau (Eds.) (2006), pp. 42-68.

Godfrey-Smith, P. \& Sterelny, K. (2016). Biological Information. In Zalta, E. (Ed.) (2016). The Stanford Encyclopedia of Philosophy (Summer 2016 Edition). Retrieved from https://plato.stanford.edu/archives/sum2016/entries/informationbiological/.

Goldberg, S. C. (2016). A Proposed Research Program for Social Epistemology. In Reider (Ed.) (2016), pp. 3-20.

Granzer, T. (2004). What Makes an Automated Telescope Robotic? Astronomische Nachrichten: Astronomical Notes $325(6$ - 8), pp. 513-518.

Griffin, R.E.M.; Hanisch, R.J.; \& Seaman, R. (Eds.) (2011). New Horizons in Time-Domain Astronomy. Proceedings of the International Astronomical Union 7(S285). Cambridge University Press.

Hankinson, R. J. (Ed.) (2008). The Cambridge Companion to Galen. Cambridge University Press.

Heather, J. \& Chain, B. (2016). The Sequence of Sequencers: The History of Sequencing DNA. Genomics 107(1), pp. 1-8.

Herculano-Houzel, S. (2009). The Human Brain in Numbers: A Linearly Scaled-up Primate Brain. Frontiers in Human Neuroscience 3, article 31. Retrieved from https://www.frontiersin.org/article/10.3389/neuro.09.031.2009.

Hipschman, R. (2019). How SETI@ home works. Retrieved from http://seticlassic.ssl.berkeley.edu/about_seti/about_seti_at_home_4.html.

Huang, W. (Ed.) (2014). Handbook of Human Centric Visualization. Springer.

Hubble Site. (2016). Hubble Site. Retrieved from http://hubblesite.org/.

Hutchinson, C. A. (2007). DNA Sequencing: Bench to Bedside and Beyond. Nucleic Acids Research 35(18), pp. $6227-6237$. Jacob, P. (2019). Intentionality. In Zalta, E. (Ed.) (2019). The Stanford Encyclopedia of Philosophy (Spring 2019 Edition).

Retrieved from https://plato.stanford.edu/archives/spr2019/entries/intentionality/.

Jacquette, D. (2006). Brentano's Concept of Intentionality. In Jacquette (Ed.) (2006), pp. 98-130.

Jacquette, D. (Ed.) (2006). The Cambridge Companion to Brentano. Cambridge University Press.

Jankovic, M. \& Ludwig, K. (Eds.) (2015). The Routledge Handbook of Collective Intentionality. Routledge.

Katz, J. (2014). What Perytons are Not, and Might Be. The Astrophysical Journal 788(1), article 34.

Kibrick, R. I. (Ed.) (2002). SPIE Proceedings Vol. 4845: Advanced Global Communications Technologies for Astronomy II. SPIE Digital Library.

Kirsh, D. (2010). Thinking with External Representations. AI \& Society 25(4), pp. 441-454.

Larkin, J. H. \& Simon, H. A. (1987). Why a Diagram is (Sometimes) Worth Ten Thousand Words. Cognitive Science 11(1), pp. 65-100.

Las Cumbres Observatory. (2019). Robotic Telescopes. Retrieved from https://lco.global/spacebook/robotic-telescopes/.

Latour, B. (1987). Science in Action: How to Follow Scientists and Engineers Through Society. Harvard University Press.

Latour, B. (2005). Reassembling the Social: An Introduction to Actor-Network-Theory. Oxford University Press.

Latour, B. \& Woolgar, S. (2013). Laboratory Life: The Construction of Scientific Facts. Princeton University Press.

Lawson, T. (2014). A Conception of Social Ontology. In Pratten (Ed.) (2014), pp. 19-52.

Lehrman, D. S.; Hinde, R. A.; \& Shaw, E. (Eds.) (1970). Advances in the Study of Behavior, Volume 3. Academic Press.

Lewens, T. (2005). Organisms and Artifacts: Design in Nature and Elsewhere. MIT Press.

List, C. \& Pettit, P. (2006). Group Agency and Supervenience. The Southern Journal of Philosophy 44(S1), pp. 85-105.

List, C. \& Pettit, P. (2011). Group Agency: The Possibility, Design, and Status of Corporate Agents. Oxford University Press.

Loiselle, M. (2017). Multiple Authority Delegation in Art Authentication. Scientonomy 1, pp. 41-53. Retrieved from https://www.scientojournal.com/index.php/scientonomy/article/view/28233.

Longino, H. E. (1990). Science as Social Knowledge: Values and Objectivity in Scientific Inquiry. Princeton University Press.

Longino, H. E. (1996). Cognitive and Non-Cognitive Values in Science: Rethinking the Dichotomy. In Nelson (Ed.) (1996), pp. 39-58.

Longino, H. E. (2019). The Social Dimensions of Scientific Knowledge. In Zalta, E. (Ed.) (2019). The Stanford

Encyclopedia of Philosophy (Summer 2019 Edition). Retrieved from

https://plato.stanford.edu/archives/sum2019/entries/scientific-knowledge-social/.

Mann, A. (2019). What is the Large Hadron Collider? Live Science January 29, 2019. Retrieved from https://www.livescience.com/64623-large-hadron-collider.html. 
Macdonald, G. \& Papineau, D. (Eds.) (2006). Teleosemantics: New Philosophical Essays. Oxford University Press.

McGrath, M. (2018). Propositions. In Zalta, E. (Ed.) (2018). The Stanford Encyclopedia of Philosophy (Spring 2018

Edition). Retrieved from https://plato.stanford.edu/archives/spr2018/entries/propositions/.

Menary, R. (Ed.) (2010). The Extended Mind. A Bradford Book.

Millikan, R. G. (1984). Language, Thought, and Other Biological Categories: New Foundations for Realism. MIT Press.

Millikan, R. G. (1989). In Defense of Proper Functions. Philosophy of Science 56(2), pp. 288-302.

Mirkin, M. (2018). The Status of Technological Knowledge in the Scientific Mosaic. Scientonomy 2, pp. 39-53. Retrieved from https://scientojournal.com/index.php/scientonomy/article/view/29645.

Morgan, A. \& Piccinini, G. (2018). Towards a Cognitive Neuroscience of Intentionality. Minds and Machines 28(1), pp. 119-139.

Nanay, B. (2006). Symmetry Between the Intentionality of Minds and Machines? The Biological Plausibility of Dennett's Account. Journal of Minds and Machines 16(1), pp. 57-71.

NASA. (2017). Tracking and Data Relay Satellite. Retrieved from https://www.nasa.gov/directorates/heo/scan/services/networks/tdrs_main.

NASA. (2018). Hubble Mission Operations. Retrieved from https://www.nasa.gov/content/hubble-mission-operations/.

NASA. (2019). Hubble Space Telescope. Retrieved from https://www.nasa.gov/mission_pages/hubble/main/index.html.

Neander, K. (2018). Teleological Theories of Mental Content. Zalta, E. (Ed.) (2018). The Stanford Encyclopedia of Philosophy (Spring 2018 Edition). Retrieved from https://plato.stanford.edu/archives/spr2018/entries/contentteleological/.

Nelson, J. (Ed.) (1996). Feminism, Science, and the Philosophy of Science. Springer.

Nicholson, D. J. \& Dupré, J. (Eds.) (2018). Everything Flows: Towards a Processual Philosophy of Biology. Oxford University Press.

Noë, A. \& Thompson, E. (Eds.) (2002). Vision and Mind: Selected Readings in the Philosophy of Perception. MIT Press.

Nutton, V. (2008). The Fortunes of Galen. In Hankinson (Ed.) (2008), pp. 355-391.

Overgaard, N. (2017). A Taxonomy for the Social Agents of Scientific Change. Scientonomy 1, pp. 55-62. Retrieved from https://www.scientojournal.com/index.php/scientonomy/article/view/28234.

Overgaard, N. (2019). On the Collective Intentionality of Epistemic Communities. Unpublished Doctoral Dissertation, University of Toronto, Toronto, ON, Canada.

Overgaard, N. \& Loiselle, M. (2016). Authority Delegation. Scientonomy 1, pp. 11-18. Retrieved from https://www.scientojournal.com/index.php/scientonomy/article/view/27065.

Palermos, S. O. \& Pritchard, D. (2016). The Distribution of Epistemic Agency. In Reider (Ed.) (2016), pp. 109-126.

Palermos, S. O. (2011). Belief-Forming Processes, Extended. Review of Philosophy and Psychology 2(4), pp. 741-765.

Palermos, S. O. (2015). Active Externalism, Virtue Reliabilism and Scientific Knowledge. Synthese 192(9), pp. $2955-2986$.

Palermos, S. O. (2016). The Dynamics of Group Cognition. Minds and Machines 26(4), pp. 409-440.

Petroff, E.; Keane, E. F.; Barr, E. D.; Reynolds, J. E.; Sarkissian, J.; Edwards, P. G.; Stevens, J.; Brem, C.; Jameson, A.; Burke-Spolaor, S.; Johnston, S.; Bhat, N. D. R.; Kudale, P. Chandra S.; \& Bhandari, S. (2015). Identifying the Source of Perytons at the Parkes Radio Telescope. Monthly Notices of the Royal Astronomical Society 451(4), pp. 3933-3940.

Pratten, S. (Ed.) (2014). Social Ontology and Modern Economics. Routledge.

Rawleigh, W. (2018). The Status of Questions in the Ontology of Scientific Change. Scientonomy 2, pp. 1-12. Retrieved from https://scientojournal.com/index.php/scientonomy/article/view/29651.

Reider, P. (Ed.) (2016). Social Epistemology and Epistemic Agency: De-Centralizing Epistemic Agency. Rowman and Littlefield.

Richter, V. (2016). The Appliance of Science in an Outback Kitchen. Nature 538(7626), p. S72.

Robertson, P. (2010). 40 Years of the Dish. ABC Science February 9, 2010. Retrieved from http://www.abc.net.au/science/articles/2010/02/09/2814525.htm.

Rumelhart, D. E. \& McClelland, J. L. (1986). Parallel Distributed Processing: Explorations in the Microstructure of Cognition Volume 2: Psychological and Biological Models. MIT Press.

Schlosser, M. (2019). Agency. In Zalta, E. (Ed.) (2019). The Stanford Encyclopedia of Philosophy (Winter 2019 Edition). Retrieved from https://plato.stanford.edu/archives/win2019/entries/agency/.

Searle, J. R. (1995). The Construction of Social Reality. Free Press.

Searle, J. R. (2006). Social Ontology: Some Basic Principles. Anthropological Theory 6(1), pp. 12-29.

Sebastien, Z. (2016). The Status of Normative Propositions in the Theory of Scientific Change. Scientonomy 1, pp. 1-9. Retrieved from https://www.scientojournal.com/index.php/scientonomy/article/view/26947. 
Seiradakis, J. \& Edmunds, M. (2018). Our Current Knowledge of the Antikythera Mechanism. Nature Astronomy 2(1), pp. $35-42$.

Schewe, K.-D. \& Williams, H. E. (Eds.) (2004). Proceedings of the Fifteenth Australasian Database Conference, ADC 2004, Dunedin, New Zealand, 18-22 January 2004. CRPIT 27. Australian Computer Society.

Shin, S.-J.; Lemon, O.; \& Mumma, J. (2018). Diagrams. In Zalta, E. (Ed.) (2018). The Stanford Encyclopedia of Philosophy (Winter 2018 Edition). Retrieved from https://plato.stanford.edu/archives/win2018/entries/diagrams/.

Siraisi, N. G. (2009). Medieval and Early Renaissance Medicine: An Introduction to Knowledge and Practice. University of Chicago Press.

Spitzer Jr, L. (1979). History of the Space Telescope. Quarterly Journal of the Royal Astronomical Society 20, pp. 29-36.

Stone, R. C.; Monet, D. G.; Monet, A. K.; Harris, F. H.; Ables, H. D.; Dahn, C. C.; Canzian, B.; Guetter, H. H.; Harris, H. C.; Henden, A. A.; Levine, S. E.; Luginbuhl, C. B.; Munn, J. A.; \& Pier, J. R. (2003). Upgrades to the Flagstaff Astrometric Scanning Transit Telescope: A Fully Automated Telescope for Astrometry. The Astronomical Journal 126(4), pp. 2060-2080.

STSI. (2019). Space Telescope Science Institute. Retrieved from http://www.stsci.edu/institute/.

Temkin, O. (1973). Galenism. Rise and Decline of a Medical Philosophy. Cornell University Press.

Theiner, G. (2014). Res Cogitans Extensia: A Philosophical Defense of the Extended Mind Thesis. Peter Lang.

Theiner, G. (2015). Group-Sized Distributed Cognitive Systems. In Jankovic \& Ludwig (Eds.) (2015), pp. 233-248.

Theiner, G.; Allen, C.; \& Goldstone, R. L. (2010). Recognizing Group Cognition. Cognitive Systems Research 11(4), pp. 378-395.

Theiner, G. \& O’Connor, T. (2010). The Emergence of Group Cognition. In Corradini \& O’Connor (Eds.) (2010), pp. 78117.

Thompson, E. (2007). Mind in Life: Biology, Phenomenology, and the Sciences of Mind. Harvard University Press.

Tollefsen, D. P. (2004). Collective Epistemic Agency. Southwest Philosophy Review 20(1), pp. 1-12.

Tollefsen, D. P. (2006). From Extended Mind to Collective Mind. Cognitive Systems Research 7(2), pp. 140-150.

Tollefsen, D. P. (2014). Social Ontology. In Cartwright \& Montuschi (Eds.) (2014), pp. 85-101.

Tuomela, R. (2002). The Philosophy of Social Practices: A Collective Acceptance View. Cambridge University Press.

Tversky, B. (2014). Visualizing Thought. In Huang (Ed.) (2014), pp. 3-40.

Vaesen, K. (2011). Giere's (In)Appropriation of Distributed Cognition. Social epistemology 25(4), pp. 379-391.

van Lawick-Goodall, J. (1970). Tool Use in Primates and Other Vertebrates. In Lehrman, Hinde, \& Shaw (Eds.) (1970), pp. 195-249.

Vestrand, W. T.; Borozdin, K. N.; Brumby, S. P.; Casperson, D. E.; Fenimore, E. E.; Galassi, M. C.; McGowan, K.; Perkins, S. J.; Priedhorsky, W. C.; Starr, D.; White, R.; Wozniak, P.; \& Wren, J. A. (2002). The RAPTOR Experiment: A System for Monitoring the Optical Sky in Real Time. In Kibrick (Ed.) (2002), pp. 126-136.

Vestrand, W. T.; Davis, H.; Wren, J.; Wozniak, P.; Norman, B.; White, R. R.; Bloch, J.; Fenimore, E.; Hogge, B.; Jah, M.; \& Rast, R. (2008). Autonomous Global Sky Surveillance with Real-Time Robotic Follow-up: Night Sky Awareness Through Thinking Telescopes Technology. In Proceedings of the 2008 Advanced Maui Optical and Space Surveillance Technologies Conference (AMOS), Wailea, Maui, Hawaii, 2008.

Vincent, J. (2016). These are Three of the Biggest Problems Facing Today's AI. The Verge October 10, 2016. Retrieved from https://www.theverge.com/2016/10/10/13224930/ai-deep-learning-limitations-drawbacks.

Walsh, D. M. (2002). Brentano's Chestnuts. In Ariew, Cummins, \& Perlman (Eds.) (2002), pp. 314-337.

Walsh, D. M. (2012). Mechanism and Purpose: A Case for Natural Teleology. Studies in History and Philosophy of Science Part C: Studies in History and Philosophy of Biological and Biomedical Sciences 43(1), pp. 173-181.

Walsh, D. M. (2015). Organisms, Agency, and Evolution: Cambridge University Press.

Walsh, D. M. (2018). Objectcy and Agency: Towards a methodological vitalism. In Nicholson \& Dupré (Eds.) (2018), pp. 167-185.

Walter, H. (2009). Neurophilosophy of Free Will: From Libertarian Illusions to a Concept of Natural Autonomy. MIT Press.

White, R.; Evans, S.; Vestrand, W.; Warren, M.; Wren, J.; \& Wozniak, P. (2006). Thinking Telescopes and the Future Astronomical Meta-Network. Astronomische Nachrichten: Astronomical Notes 327(8), pp. 758-762.

Wimsatt, W. C. (2006). Aggregate, Composed, and Evolved Systems: Reductionistic Heuristics as Means to More Holistic Theories. Biology and Philosophy 21(5), pp. 667-702.

Wimsatt, W. C. (2007). Re-Engineering Philosophy for Limited Beings: Piecewise Approximations to Reality. Harvard University Press.

Zeilik, M. \& Gregory, S. (1998). Introductory Astronomy and Astrophysics. $4^{\text {th }}$ Edition. Brooks Cole. 